No. 20-8

\title{
Real Effects of Foreign Exchange Risk Migration: Evidence from Matched Firm-Bank Microdata
}

\author{
Puriya Abbassi and Falk Bräuning
}

\begin{abstract}
:
When firms trade forward contracts with banks to protect foreign currency cash flows against exchange rate movements, foreign exchange risk migrates to the banking sector. We show how this migrated risk may induce systemic repercussions with severe implications for the real economy. For identification, we exploit the Brexit referendum in June 2016 as a quasi-natural experiment in combination with detailed microdata on forward contracts and the credit register in Germany. Before the referendum, firms substantially increased their use of derivatives in response to the heightened uncertainty; banks, in providing these contracts, did not fully intermediate the risk and retained a large share of it on their own books. The depreciation of the British pound in response to the referendum's outcome posed a shock to the capital of ex ante exposed banks. Banks, especially weakly capitalized ones, absorbed these losses by cutting back credit to all firms, including those unlikely to have had any exchange rate exposure to begin with. Firms that had ex ante borrowing relationships with banks facing losses experienced a larger reduction in credit and a greater decline in investment compared with their industry peers, thereby contributing to the aggregate investment contraction. We also find these effects to be more pronounced for small firms, which is consistent with credit market frictions being rooted in asymmetric information problems.
\end{abstract}

JEL Classifications: D53, D61, F31, G15, G21, G32

Keywords: credit supply, foreign exchange risk, financial intermediation, risk migration, financial stability

Puriya Abbassi is a principal financial stability expert at the Deutsche Bundesbank; his email is puriya.abbassi@bundesbank.de. Falk Bräuning is a senior economist in the research department of the Federal Reserve Bank of Boston; his email is falk.braeuning@bos.frb.org. The authors thank participants at the Boston MacroFinance Junior Seminar, the Federal Reserve System Banking Conference, Deutsche Bundesbank Seminar, and the ASSA Day Ahead Conference. They also thank Pol Antràs, Omar Barbiero, Joaquin Blaum, Ricardo Correa, Wenxin Du, Alexander Falter, José Fillat, Galina Hale (discussant), Victoria Ivashina, Raj Iyer, Gustavo Joaquim, Ralph Koijen, Thomas Krön, Thilo Liebig, Jens Lindemann, Christoph Memmel, Ali Ozdagli, Joe Peek, Julia Schmidt (discussant), Benjamin Weigert, and Daniel Werner for valuable comments and discussions. The first draft of this paper is from April 2019. This paper presents preliminary analysis and results intended to stimulate discussion and critical comment. The views expressed herein are those of the authors and do not indicate concurrence by Deutsche Bundesbank, the Eurosystem, the Federal Reserve Bank of Boston or the Federal Reserve System. This paper, which may be revised, is available on the website of the Federal Reserve Bank of Boston at https://www.bostonfed.org/publications/research-department-working-paper.aspx.

This version: July 2020

https://doi.org/10.29412/res.wp.2020.08 


\section{Introduction}

With an annual turnover of more than $\$ 250$ trillion, the market for foreign exchange risk protection has become one of the most important markets available today (Figure 1). The rapid growth of the forward market during the past decades is intrinsically related to the well-established deepening of economic globalization through international trade (e.g., Krugman 1995; Bordo et al. 2003). ${ }^{1}$ In particular, firms that are active in international product and factor markets face cross-currency cash flows and reduce the associated exchange rate risk using forward contracts (e.g., Ethier 1973), thereby transferring the risk to their forward counterparties. However, while hedging the foreign exchange exposure may be prudent from an individual firm's risk management perspective, we argue that this migration of risk may have important macroeconomic implications.

More specifically, because banks are central dealers in derivatives markets (e.g., Duffie 2010), the migration of foreign exchange risk may have an especially profound effect on the economy through its impact on the banking system. In particular, if the migrated risk remains in the banking sector and is not fully intermediated to other parties, such as firms, an exchange rate shock may induce systemic repercussions with severe implications for the real economy. A key transmission mechanism, which we formalize in a stylized model in this paper, may operate through equity losses at banks with imperfect intermediation of the migrated exchange rate risk; in turn, this may lead to a reduction in their credit supply as capital constraints bind, thereby hampering firms' ability to borrow and invest and triggering a reduction in economic activity.

To test this channel empirically, we exploit the period leading up to and immediately following the United Kingdom's referendum to leave the European Union (Brexit referendum hereafter) in 2016. This period serves our purpose for two main reasons. First, the period between the announcement of the referendum on February 22, 2016, and the actual referendum on June 23, 2016, is characterized by increasing uncertainty, creating heightened awareness of foreign exchange risk. This period is excellent for identification, as it allows us to study how exposed firms respond to this

\footnotetext{
${ }^{1}$ Several papers highlight the increasing role of international trade and the expanding globalization of value chains for the growth of firms' businesses and profits. (e.g., Yi 2003; Broda and Weinstein 2006; Antras et al. 2017).
} 
Figure 1: Growth of Foreign Exchange Forward Market and International Trade

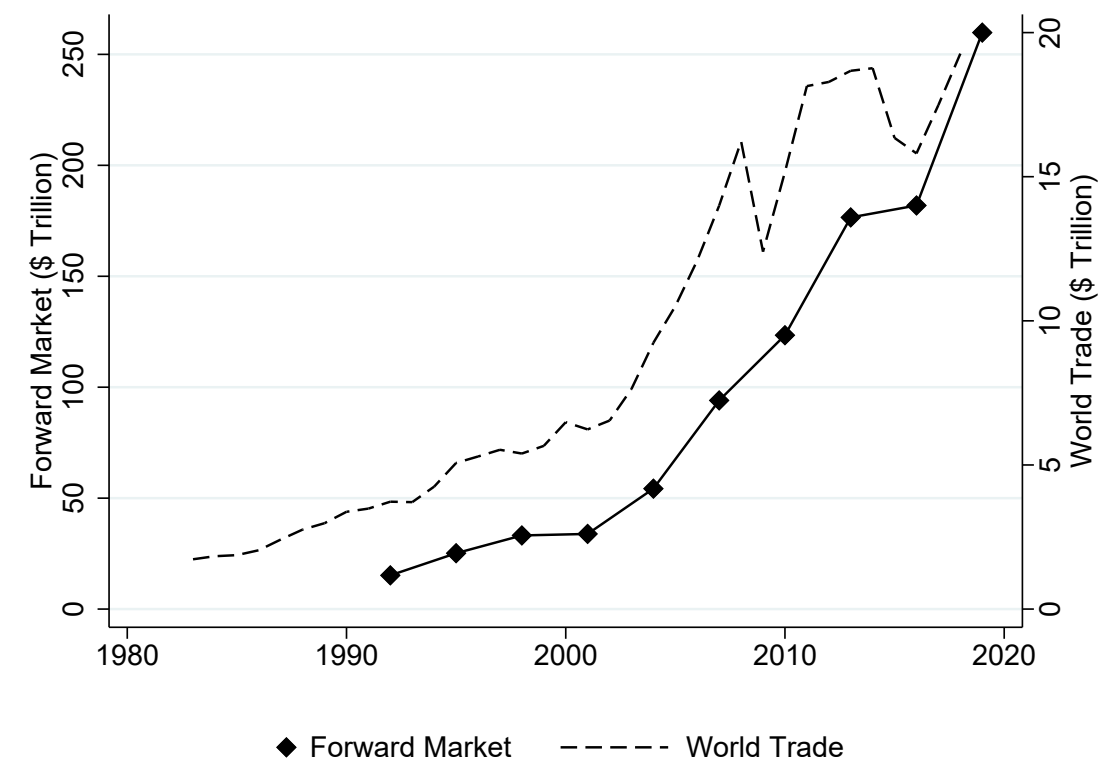

Notes: The figure shows the annualized value of foreign exchange forward turnover and the annual value of total trade flows. Source: Foreign exchange forward data are from the Bank for International Settlement's Triennial Central Bank Survey of Foreign Exchange and Over-the-counter (OTC) Derivatives Markets. The annual trade data are retrieved from the International Monetary Fund and are based on freight-on-board (FOB) export values.

elevated risk in British pound (GBP) exchange rate markets and how banks position themselves visà-vis potential demand shifts from the nonfinancial sector. Second, the outcome of the referendum caused the pound to depreciate 12 percent against the euro and similarly against all other major currencies. The period following the exchange rate shock hence allows us to study how unbalanced foreign exchange exposure before such a shock may unravel and affect individual counterparties, broader financial markets, and the real economy after the exchange rate risk materializes.

For the second key component of our empirical identification, we assemble a unique combination of supervisory microdata sources from Germany. ${ }^{2}$ More precisely, we obtain comprehensive transaction-level data of all foreign exchange forward contracts with German banks, enabling us to trace the foreign exchange risk migration before the referendum date at the bank-firm level,

\footnotetext{
${ }^{2}$ Germany is a large exporting country and is the second-largest trade partner of the United Kingdom, with exports to the United Kingdom worth 89 billion euros in 2015.
} 
including important cross-industry heterogeneity in hedging demand. ${ }^{3}$ Moreover, because we have detailed on-balance-sheet information about banks' foreign-currency assets and liabilities, we can measure actual changes in a bank's overall exposure to the pound in response to the risk migration, given that on-balance-sheet positions may adjust in response to changes in a bank's derivatives exposure. In addition, our analysis crucially relies on granular lending information from the German credit register at the bank-firm level to estimate post-referendum adjustments in credit supply. ${ }^{4}$ Finally, we use firms' income statements and balance sheet data to examine the impact on the real economy.

Our robust key results can be summarized as follows. For the period between the referendum's announcement and its actual date, we find that (nonbank) firms increased their use of forward derivatives (measured by gross notional value of GBP forward contracts) with German banks by about 23 percent on average. Consistent with our model, the increase in hedging coincided with elevated exchange rate uncertainty. Moreover, we find this increase in derivatives contracts for firms that committed to buying pounds forward (long exposure) and those that agreed to sell pounds forward (short exposure), leading to small net exposure in the aggregate. However, this aggregate view masks important cross-industry heterogeneity in firms' net short exposures (that is, the difference between short and long positions) to the post-Brexit pound value. For example, for the consumer discretionary sector we find a buildup of large net short GBP exposures (46.5 percent of gross exposure), while the materials sector accumulated large net long GBP positions (17.99 percent of gross exposure)..$^{5}$

We find that banks, as counterparties to firms, increased their supply of GBP forwards in the period before the referendum date, but with sizable and growing heterogeneity in their net derivatives position, suggesting that some banks did not fully intermediate the migrated risk. In fact, about

\footnotetext{
${ }^{3}$ In GBP hedging markets, as with other currencies, forward contracts represent the bulk of foreign exchange hedges, with options or others having only marginal relevance for nonfinancial firms' exchange risk hedging. For example, during our sample period, notional values of GBP forwards were about 25 times larger than the notional values of GBP options.

${ }^{4}$ The derivatives and credit data include all contracts with German banks, irrespective of the nationality of the counterparty, thus drawing a comprehensive picture of banks' exposure.

${ }^{5}$ While we do not observe actual foreign exchange exposure at the firm level, as part of our analysis, we show that net GBP derivatives positions were driven by industry-specific net exports to the United Kingdom.
} 
20 percent of the banks had accumulated an exposure of at least 15 percent of their equity value before the referendum date. We show that a bank's net GBP derivatives exposure at the referendum date is closely linked to skewed client demand stemming from (ex ante) industry concentration among its derivatives clients. For example, banks that supplied derivatives to industries with an increased demand for net short positions in the run-up to the referendum tended to have a net long exposure just before the Brexit referendum and higher losses after the referendum when the contracts matured. ${ }^{6}$ Importantly, the tight link between industry concentration and net derivatives exposure holds after we control for banks' on-balance-sheet net GBP assets, which could potentially offset the risks from a nonzero derivatives exposure. Consistent with our model's prediction, we also show that price adjustments in the forward market are a key mechanism in the risk allocation. In particular, banks, which face a skewed industry demand that leads to net derivatives exposure, obtain a more favorable forward premium on contracts that add to their net exposure. (At the same time, we find that banks reinsure about 87 percent of their skewed client demand in the interbank market, but they do so at increasing costs, which reduces banks' spreads.)

After the referendum, the pound's value plummeted about 12 percent relative to the euro, and banks with a (net) long GBP derivatives exposure incurred losses. Using marked-to-market valuation of individual forward contracts, we show that for 10 percent of banks the loss was larger than 10 percent of their equity value. These losses in turn affected credit supply: Banks that experienced large losses from their GBP derivatives exposure (and thus an adverse shock to their net worth) cut back credit to firms. We identify these supply effects using a difference-in-differences regression approach in combination with instrumental variables estimation. Specifically, we exploit withinborrower variation in credit growth after the Brexit referendum, which we link to heterogeneous derivatives losses across banks. ${ }^{7}$ By comparing different banks' credit growth for the same borrower in the same quarter, we effectively control for a potential reduction in a firm's credit demand after the

\footnotetext{
${ }^{6} \mathrm{We}$ measure banks' industry concentration based on all derivatives contracts before the announcement of the referendum. Our results are insensitive to the precise choice of reference period, as banks' industry concentration in derivatives clients is stable over time. Moreover, a bank's industry concentration in the derivatives book is closely mirrored in its credit book, and a large share of a bank's derivatives clients are also its borrowers.

${ }^{7}$ We do not find a differential trend in pre-Brexit credit growth depending on banks' post-Brexit derivatives losses, supporting the validity of our identification approach.
} 
referendum (Khwaja and Mian 2008). To identify exogenous variation in derivatives losses across banks, we instrument losses with banks' heterogeneous industry concentration in their derivatives books. ${ }^{8}$ Our baseline estimate indicates an average elasticity of -0.73 , suggesting that for a 1 percentage point derivatives loss, a bank cuts back credit by 73 basis points, on average. Consistent with the notion of capital constraints being binding, this effect is substantially stronger for banks with a lower equity-to-assets ratio.

The post-Brexit credit-supply contraction induced by banks' exchange rate losses has had aggregate effects on firms' funding conditions and real economic activity. In particular, our firmlevel analysis shows that firms with a strong dependence on banks that suffered derivatives losses also experienced an overall cutback in credit after the referendum; that is, they were not able to substitute the loss of funding by increasing borrowing from other banks, which is consistent with previous evidence on the lack of substitutability of bank credit relationships, which may be rooted in asymmetric information problems (e.g., Petersen and Rajan 1995; Chodorow-Reich 2013). This overall credit contraction for affected firms is about 32 percent stronger than the average credit contraction after the Brexit referendum and is also present for nonfinancial firms. Moreover, we also show that firms without any derivatives usage - those that likely did not have any exposure to foreign exchange risk-experienced a credit reduction from banks facing derivatives losses. Finally, we trace the transmission to real activity by showing that German nonfinancial firms with strong ex ante credit relationships with banks facing losses reduced investment about 2 percentage points more than firms without ties to those banks, thereby strongly contributing to the overall decline in aggregate private investment in Germany in the aftermath of the referendum. We also find that, consistent with credit market frictions (e.g., Gertler and Gilchrist 1994), the adverse effects on credit and investment are concentrated in small firms.

\footnotetext{
${ }^{8}$ More precisely, we interact bank-level industry shares before the announcement with industry-level net hedging demand after the announcement, but before the Brexit referendum. Thus, our instrument is closely related to the Bartik or shift-share instrument. While the Bartik instrument was originally applied in the context of labor markets, recent work has used Bartik-type instruments to study the real effects of credit market shocks (e.g., Greenstone et al. 2020).
} 
Related Literature. Our paper contributes to several strands of the literature. First, it relates to the broad literature that studies the effect of foreign exchange market dynamics on firms. One set of studies focuses on the effects of changes in the foreign exchange rate on exporters and importers (e.g., Desai et al. 2008; Berman et al. 2012; Amiti et al. 2014). Other papers in this area highlight how, especially in emerging markets, firms that have unhedged foreign currency debt find their net worth deteriorating after a large depreciation of domestic currency hampers their ability to borrow and invest (e.g., Caballero and Krishnamurthy 2003; Aghion et al. 2004; Hale and Arteta 2009). We contribute to this literature by identifying a distinct channel whereby an exchange rate shock affects firms' credit availability and production, even if those firms are not exposed to foreign exchange risk through international product or factor markets. ${ }^{9}$

Second, we relate to the large body of research that studies how shocks to banks affect their lending behavior and real activity (e.g., Bernanke and Gertler 1989; Holmstrom and Tirole 1997; Gertler and Kiyotaki 2010; Brunnermeier and Sannikov 2014). In the context of international shock transmission, the seminal work by Peek and Rosengren $(1997,2000)$ documents how a domestic shock to the capital base affects international lending behavior of global banks (see also, e.g., Schnabl 2012; Morais et al. 2019). We also document that, after a negative shock to net worth (originating in a foreign country), banks cut back credit supply across their entire credit book. Our finding that the shock has real implications is also related to several recent papers that, using (matched firm-bank) microdata, show how shocks to banks transmit to the real economy (e.g., Amiti and Weinstein 2011; Chodorow-Reich 2013; Paravisini et al. 2015).

Third, our paper contributes to an emerging literature that studies the interrelation between foreign exchange markets and banking activity, in particular, credit provision. For example, recent studies suggest that banks strongly influence foreign exchange rates. Gabaix and Maggiori (2015) argue that financial intermediaries' risk-taking capacity crucially affects foreign exchange rates. In the forward market, empirical results suggest that banks' leverage constraints or foreign-currency

\footnotetext{
${ }^{9}$ In the context of the exchange rate pass-through to prices, a large literature highlights the importance of the assumed invoicing currency of international trade (e.g., Gopinath et al. 2020, and the references therein). In our analysis, we exploit shifts in firms' hedging demand to cover exchange rate exposure, which in general depends on the trading partners' invoicing currency.
} 
mismatches affect exchange rates (e.g., Du et al. 2018; Abbassi and Bräuning 2020). Conversely, foreign exchange rates also influence banks' lending decisions. For example, Ivashina et al. (2015) and Bräuning and Ivashina (2016) show that global banks reduce their foreign-currency lending in response to higher forward premia. Similarly, Bruno and Shin $(2014,2015)$ show that cross-border credit adjusts when the dollar exchange rate moves. In all these papers, bank leverage interacts with the exchange market. Our findings closely relate to these studies, but we show a distinct connection between bank credit supply and the foreign exchange markets operating through foreign exchange derivatives exposure.

Fourth, our paper fits into the literature that studies risk management practices by entities (e.g., Froot et al. 1993; Froot and Stein 1998; Rampini and Viswanathan 2018; Rampini et al. 2020). In this regard, our paper especially relates to the growing literature that studies the financial stability effects of banks' risk exposures more generally and derivatives exposures in particular (e.g., Brunnermeier et al. 2011; Begenau et al. 2015; Duffie 2010). Some of this literature shows that moral hazard problems on the insurer side can emerge from risk migration through derivatives contracts (e.g., Thompson 2010). In this paper, we identify an important channel of risk migration and demonstrate its strong effect on the real economy.

The remainder of this paper is organized as follows. In Section 2, we describe our theoretical framework and empirical setup. In Section 3, we discuss the data. Section 4 presents our empirical

results. Section 5 concludes. The Appendix contains details of the theoretical framework as well as additional figures and tables.

\section{Theoretical Framework and Empirical Setup}

To structure and guide our empirical analysis, we set up a stylized two-period model of foreign exchange risk migration, building on the micro model of a firm's hedging choice in Froot et al. (1993), but introducing a capital-constrained bank that provides financial services to the firm. In period 0 , the firm enters a derivatives contract with the bank to hedge the value of its period-1 
wealth, which is subject to foreign exchange risk (for example, due to foreign currency income from exports or foreign sales). In period 1, the foreign exchange risk materializes and affects the firm's equity value. The firm produces output in period 1 using equity, subject to a concave production technology. Because the firm is financially constrained, it must fund part of its investment by borrowing from the bank in period 1. Due to the concavity in the firm's profit function, it wants to insulate its equity value from random fluctuation associated with exchange rate risk. The key parameter of the model is the uncertainty about the period-1 exchange rate. We present our full model and the equilibrium in the derivatives and credit markets in detail in Appendix A to preserve space for our extensive empirical analysis. Here, we state the following key testable predictions emerging from this stylized model that will guide our empirical analysis.

Hypothesis 1. As exchange rate uncertainty increases, firms' hedging demand increases. Depending on the exposure, firms will increase their demand for net short or net long positions.

Hypothesis 2. Banks provide the additional insurance to firms at an increasing cost (forward premium increases) and absorb the resulting net derivatives exposure on their books.

Hypothesis 3. If the foreign currency depreciates, banks' long derivatives positions induce equity losses, thereby reducing the capacity to provide credit to firms (binding capital constraint).

Hypothesis 4. After the exchange rate shock, firms that rely on credit from loss-bearing banks face reduced credit availability and contract their investment.

To empirically test these effects of foreign exchange risk migration, we exploit the UK referendum to leave the European Union on June 23, 2016, as a quasi-natural experiment. The Brexit referendum date was first announced by then-prime minister David Cameron in a speech to the House of Commons on February 22, 2016. The Brexit announcement and referendum provide an ideal setup to empirically assess theoretical predictions, as they closely resemble the model setup. In response to the announced referendum, uncertainty about the future value of the British pound (that is, for the period immediately after the Brexit referendum) increased substantially, as the outcome of the referendum was not clear; after the referendum, the value of the pound dropped substantially. 
Table 1: Forecast Distribution for Post-Brexit-Referendum USD/GBP Rate

\begin{tabular}{lccc}
\hline & \multicolumn{2}{c}{ Forecasts of July 2016 rate made } \\
& $\begin{array}{c}\text { before Announcement } \\
\text { (January 2016) }\end{array}$ & $\begin{array}{c}\text { after Announcement. } \\
\text { (April 2016) }\end{array}$ & $\begin{array}{c}\text { \% Change } \\
(1)\end{array}$ \\
\hline Mean & 1.50 & $(2)$ & $(3)$ \\
Range (Max-Min) & 0.11 & 1.44 & -4.00 \\
Relative Range (\%) & 7.33 & 0.17 & 54.55 \\
\hline
\end{tabular}

Notes: The range of the forecast distribution is a measure of exchange rate uncertainty. Relative Range is the range of the forecast distribution relative to its mean (in percent). The announcement of the Brexit referendum was on February 22, 2016. Sources: Consensus Economics and authors' calculations.

Table 1 mirrors the increase in uncertainty about the pound's post-referendum value by showing key Economic Consensus statistics concerning the distribution of the pound's value vis-à-vis the US dollar for July 2016. These forecasts were taken at two distinct points in time before the actual referendum. One group is from January 2016 (that is, six-month-ahead forecasts), and the other is from March 2016 (that is, three-month-ahead forecasts). Economic Consensus data provide both the mean and the range of the forecast distribution, allowing us to distinguish between the expected future exchange rate and the uncertainty about the future exchange rate. Two observations stand out. First, the mean forecast for the USD/GBP rate to prevail in July 2017 shifted, albeit rather mildly, indicating a depreciation of about 4 percent between January and March. Second, and most strikingly, the distribution of the forecasts widened substantially, as indicated by an increase in the range of individual forecasts of more than 50 percent.

A similar picture of the pre-referendum uncertainty about the pound's value arises from marketbased measures of future currency volatility. Figure 2, Panel (a), shows a strong increase in the Cboe/CME FX British Pound 30-Day Volatility Index, a forward-looking measure that is designed to capture the market's expectation of future USD/GBP volatility. The volatility index strongly increased in May 2016 (as the 30-day window moved closer to the referendum date of June 23) and peaked just before the actual referendum. After the referendum, the index quickly subsided to levels similar to those that prevailed at the beginning of 2016. This reduction in volatility occurred despite 
Figure 2: GBP Pre-Brexit Uncertainty and Post-Brexit Devaluation

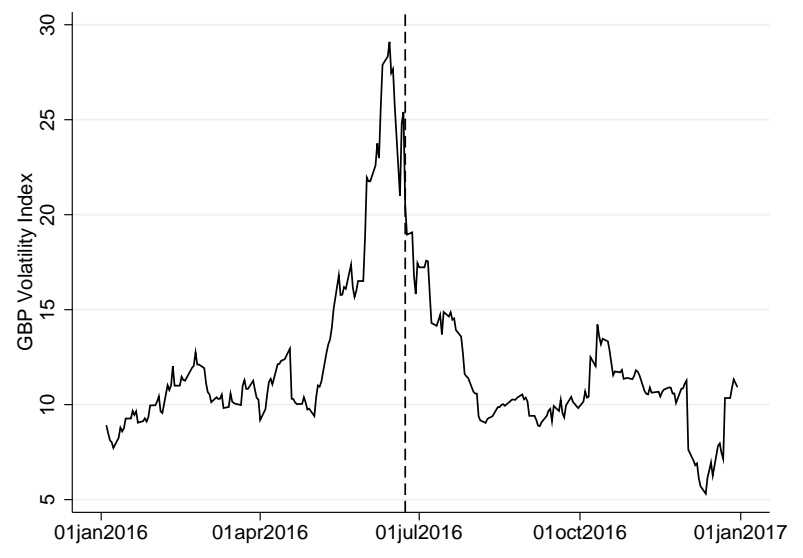

(a) Exchange Rate Volatility Index

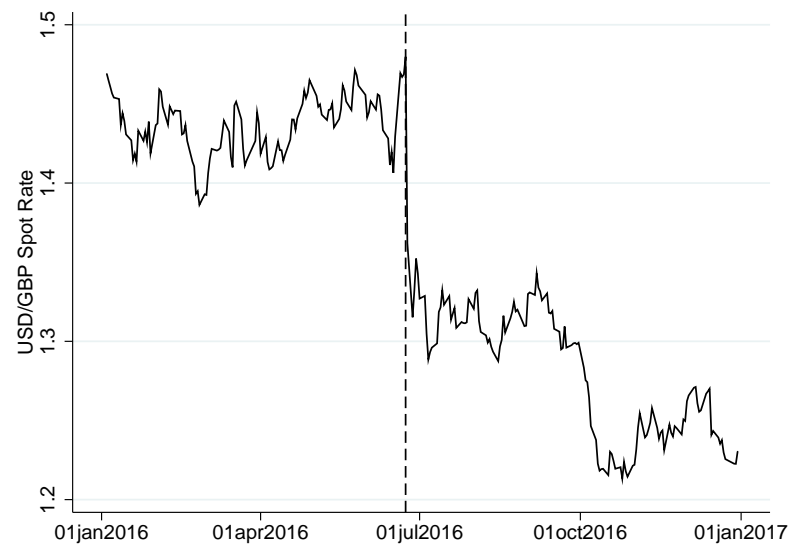

(b) Spot Exchange Rate

Notes: Panel (a) shows the Cboe/CME FX British Pound 30-Day Volatility Index, which measures the market's expectation of future (30-day) currency-related volatility. Panel (b) shows USD/GBP spot exchange rate. Vertical dashed line indicates Brexit referendum date of June 23, 2016. Sources: Bloomberg and authors' calculations.

the fact that after the British voted to leave the European Union, the pound's value fell dramatically against all major currencies. Figure 2, Panel (b), shows that the USD/GBP rate fell about 10 percent in the days after the referendum and remained at those levels in the period thereafter. ${ }^{10}$ Thus, the resolution of the uncertainty about the outcome of the Brexit referendum led to a substantial decrease in exchange rate uncertainty.

We exploit these dynamics around the Brexit referendum to link our theoretical predictions to our empirical analysis. First, we investigate firms' use of GBP forwards in response to increased exchange rate uncertainty (that is, the period after the announcement but before the referendum date), and how banks supplied those derivatives and managed the resulting foreign exchange risk migration. Second, we look at the post-Brexit-referendum period when the foreign exchange risk materialized and banks with exposure to the pound incurred losses or gains from their derivatives positions supplied before the referendum. In particular, we analyze differential changes in credit

\footnotetext{
${ }^{10} \mathrm{~A}$ similar depreciation of the pound against the euro is shown in Appendix Figure A2, which also confirms that while the pound lost value, other major currency pairs remained stable after the Brexit referendum. Later, in early October of 2016, the pound depreciated further in response to Prime Minister Theresa May's announcement that the United Kingdom would begin the formal Brexit negotiation by the end of March 2016.
} 
supply by loss-bearing banks (versus non-loss-bearing banks) and the potential real effects for the corporate sector.

\section{Data Description}

We use four key data sources in our analysis. First, and at the core of our empirical analysis, we use detailed supervisory data on exchange rate derivatives that we obtained from the Deutsche Bundesbank, which, in conjunction with the European Central Bank and the German Federal Financial Supervisory Authority (BaFin), is the prudential bank supervisor in Germany. More precisely, the European Markets Infrastructure Regulation (EMIR)— the European analog to the US Dodd-Frank Act—grants the Deutsche Bundesbank access to all derivatives trades involving at least one party that is based in Germany. The raw data that we observe include detailed information on all foreign exchange derivatives contracts, including information on the contracting parties, the initiation day, the contract maturity, the type of contract, the trading capacity (on the party's own account or agent trades), the currency traded, the notional value (expressed in both currencies), the price (or rate), and the type of collateralization. For our analysis, we focus on the most liquid and most economically relevant foreign exchange derivatives market and restrict the data to forward contracts, which, together with foreign exchange swaps, are by far the most frequently used foreign exchange derivatives contracts (forwards and swaps account for about 93 percent of all foreign exchange derivatives contracts in our sample). ${ }^{11}$ Given the focus of our research question, we devote our attention to all forward transactions that involve the British pound (henceforth GBP derivatives); that is, we look at both forward sales and purchases of the pound-those contracts that are primarily used for hedging purposes.

Second, we use proprietary data on the external positions of banks (AUSTA - Auslandsstatus). These reports are maintained by the Deutsche Bundesbank and provide, for each bank in Germany,

\footnotetext{
${ }^{11}$ However, foreign exchange swaps are funding instruments and not used by firms for hedging purposes. Hedging instruments other than forwards, including options, which account for roughly 7 percent of all foreign exchange derivatives contracts in our sample, are of only marginal relevance. Also, in terms of notional values, the forward turnover is about 25 times larger than that of options.
} 
comprehensive information on all non-euro-denominated claims and liabilities (those held domestically and those held abroad) at the currency level in each month (stock at the end of each month). In addition, the reports include information on the maturity and on the sector (interbank, retail, or affiliated offices) that are related to the liability or asset position, respectively (Gomolka et al. 2020a). This data set is important for our analysis because it allows us to take stock of banks' foreign-currency-denominated assets and liabilities. Moreover, this information allows us to study whether banks fully intermediate the foreign exchange risk in which they engage when meeting firms' foreign exchange risk management demand (which is the main question this paper explores). In particular, on-balance-sheet exposure, in combination with derivatives (off-balance-sheet) exposure, allows us to comprehensively assess the overall currency exposure of each bank. We scale these exposure measures by bank-level balance sheet information (BISTA), notably total assets and equity, which is maintained by the Bundesbank (Gomolka et al. 2020b).

Third, we have access to the supervisory credit register from the Deutsche Bundesbank (Credit Register of Loans of EUR 1 Million or More). Banks are required to report, at a quarterly frequency, all exposures with individual borrowers whose overall credit exposure equals EUR 1 million or more. Note that lending to small and medium-sized firms is not fully covered by this data set. However, the credit register is estimated to cover around 70 percent of the total credit volume in Germany. The credit register provides information at the borrower level on the value of committed loans that are outstanding for each bank in each quarter. Similar to the AUSTA data and the derivatives data, the information is at the bank level, as opposed to the bank holding company level. Moreover, the credit register identifies each borrower's industry code and country of residency. ${ }^{12}$

Fourth, we use Bureau van Dijk's Orbis data on firms' annual financial information. This data set provides multiple variables, including the number of employees, investment, and total assets. ${ }^{13} \mathrm{We}$ also use several other data sources, including Orbis, Bundesbank internal supervisory information, Capital IQ, and hand-collected information, to merge and combine the economic sector of each firm

\footnotetext{
${ }^{12}$ The credit register, however, does not record the maturity, collateral, currency denomination, or interest rate associated with the loans.

${ }^{13}$ The matching of this data with the previous sources is done using a machine learning approach. For more details, see (Schild et al. 2017)
} 
in our data sets. ${ }^{14}$

\section{Empirical Results}

\subsection{Foreign Exchange Risk Management and Migration}

\subsubsection{Firms' Response to the Announcement of the Brexit Referendum}

Based on our model's predictions, we conjecture that the increased uncertainty about the British pound's value after the Brexit referendum led to a surge in demand for GBP forward contracts by (nonbank) firms to hedge against pound exposure. ${ }^{15}$ Consistent with this conjecture, Figure 3 shows an increase in the weekly gross notional values of the British pound sold and bought in the forward market by nonbank businesses before the Brexit referendum in June 2016. The weekly value of the notional contracts increased from an average of about GBP 50 billion in the pre-announcement period to a record high of about GBP 80 billion in the week of the Brexit referendum. We find that firms increased their gross derivatives use about 23 percent after the announcement of the referendum, on average. ${ }^{16}$ Consistent with a demand-driven increase in hedging activity, we also find that bid-ask spreads in the forward market widened substantially in the run-up to the Brexit referendum (Appendix Figure A3). Prices and quantities in the forward market both comoved strongly with the GBP uncertainty measure (Appendix Table A1). In fact, when the exchange rate

\footnotetext{
${ }^{14}$ In the credit data set, the industry information is part of banks' supervisory reporting requirement and available for all borrowers. The Bundesbank internal industry identifier, however, is different from those available in the derivatives data set, for which we merge in information retrieved from Orbis, CapitalIQ, and web scraping. We then combine industry sector information across these two data sources and map all industry classifications to a common S\&P two-digit Global Industry Classification Standard (GICS). Overall, we are able to identify the industry for 48 percent of the firms (which include some very small firms) in the derivatives data set. These firms account for 77 percent of all transactions.

${ }^{15}$ In our model, firms' use of forward contracts is tied to hedging purposes, that is, to prudent risk management. In the data, we do not observe the underlying economic motive for the firms' use of forwards. Thus, although we believe this is rather unlikely, we cannot rule out entirely that firms may use forwards to speculate on exchange rate movements. In any case, any use of derivatives will lead to a risk reallocation.

${ }^{16}$ See Appendix Table A1. Given the general short-term nature of the forward market, most of the increase in hedging activity occurred just a couple of weeks before the actual Brexit referendum date. Appendix Table A2 shows summary statistics of firms' GBP forwards use both before and after the referendum was announced, confirming increased hedging activity (larger notional values, more contracts) and a slight maturity extension as the referendum date approached.
} 
uncertainty subsided after the Brexit referendum, the forward market turnover and bid-ask spreads reverted to levels observed before the referendum announcement.

Figure 3: Aggregate Gross and Net Nationals of Firms' GBP Forward Contracts

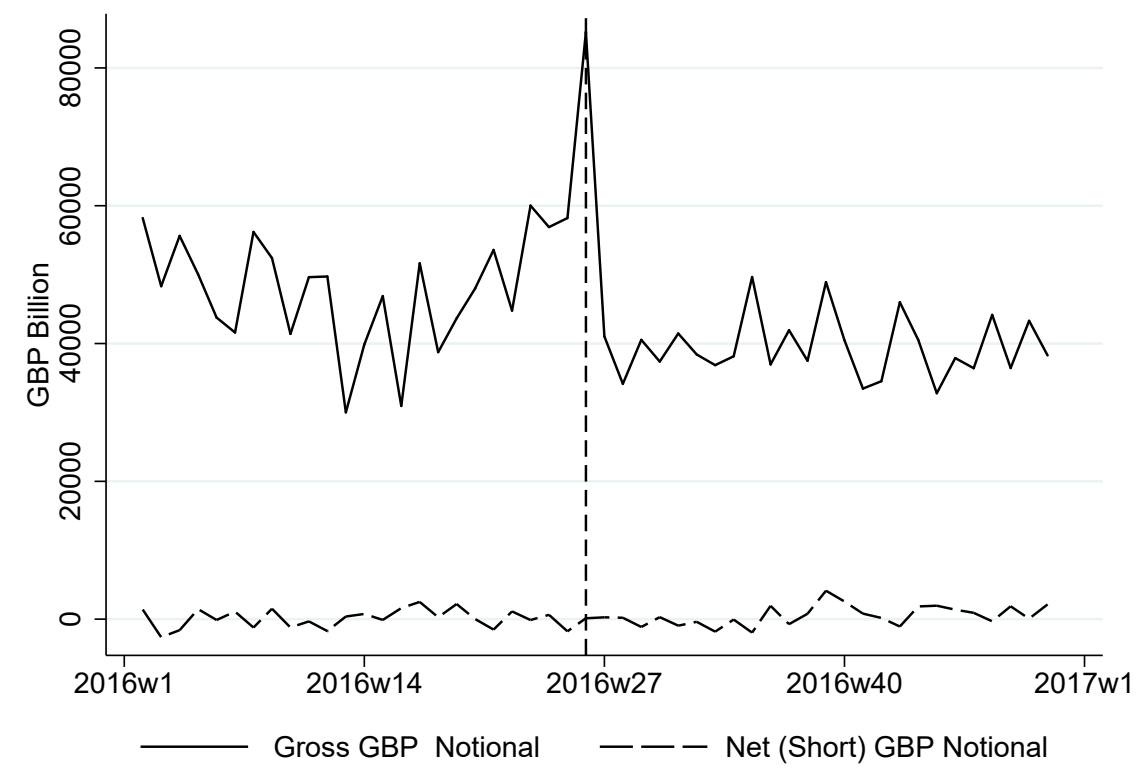

Notes: This figure shows the weekly total notional value of gross (solid line) and net short (dashed line) GBP derivatives positions entered by nonbank firms. The sample includes all contracts between (nonbank) firms and German banks. The vertical line indicates the Brexit referendum on June 23, 2016. Sources: Supervisory transaction-level derivatives available under European Markets Infrastructure Regulation (EMIR) and authors' calculations.

Figure 3 also shows that in the period before the referendum date, the (nonbank) firm sector increased its short and long exposure in aggregate by about the same magnitude, as net short positions are stable and close to zero. However, this aggregate view masks important variation in net hedging demand across firms, in particular, across i ndustries. These heterogeneous demand shifts, which we take as given, may result from heterogeneity in GBP exposures due to differences in net exports, foreign sales, or the degree of vertical specialization across countries.

Therefore, in Figure 4, we plot, by industry, the monthly cumulative net (short) positions entered before the referendum date. (We plot the data at the monthly frequency instead of the weekly frequency to comply with confidentiality agreements with the data $\mathrm{p}$ rovider.) Given our focus on post-Brexit exposure, we consider only contracts that matured after the referendum date; that is, contracts that were used to hedge post-Brexit GBP exposure. We normalize, by industry, the 
cumulative net exposure and express it as a percentage of the cumulative gross notional value at the referendum date. The figure reveals a large and growing heterogeneity in net exposure across industries. At the referendum date, firms with particularly large relative net exposure, including consumer discretionary (46.54 percent), communication services (32.12 percent), and information technology (27.03 percent), had the largest net short exposure. Banks that acted as counterparties to these sectors thus had a net long exposure that—if not hedged—-triggered losses when the pound's value fell. Indeed, the number of sectors that had net short exposure was greater than the number that had net long exposure. On the other end, we find that energy $(-15.19$ percent $)$ and materials (-17.99 percent) built up relative large net long exposure before the Brexit referendum, implying that banks that provided these contracts had net short exposure vis-à-vis these sectors. Also, financials had relatively small net long exposure at the referendum, while the pound value of the net long exposure was large compared with other industries. The detailed final net position by industry at the referendum date is reported in Appendix Table A3. ${ }^{17}$

Figure 4: Cross-Industry Heterogeneity in Net Short Positions in Post-Brexit Pound Value
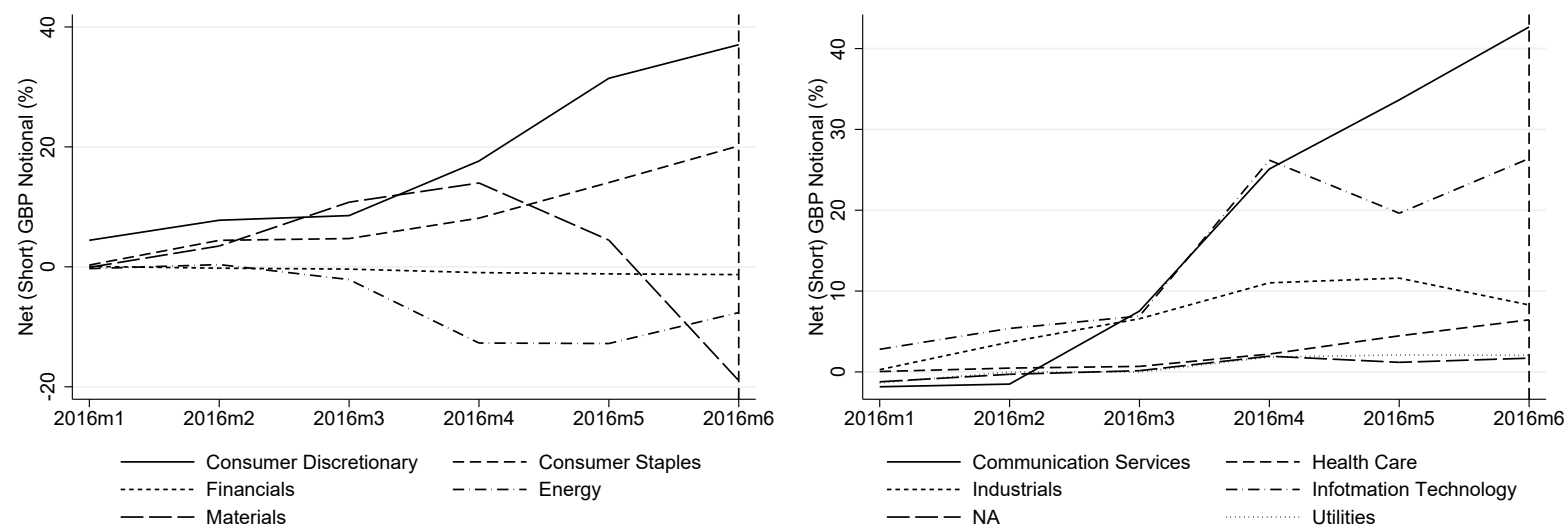

Notes: This figure shows the cross-industry heterogeneous buildup of net exposure in the post-Brexit pound value. The figure shows, by industry, monthly cumulative net (short) GBP positions, expressed as a percentage of the total gross notional contract value at the time of the Brexit referendum. $N A$ includes firms without an identified industry classification. Firms are grouped into industries following the $\mathrm{S} \& \mathrm{P}$ two-digit Global Industry Classification Standard (GICS). For detailed exposure values at the referendum date, see Table A3. The vertical line indicates the Brexit referendum on June 23, 2016. The data points for $2016 \mathrm{~m} 6$ include only contracts initiated before the Brexit referendum. Sources: Supervisory transaction-level derivatives available under European Markets Infrastructure Regulation (EMIR) and authors' calculations.

\footnotetext{
${ }^{17}$ In Appendix Table A4, we show that a firm's net hedging is significantly related to its net trade with the United Kingdom.
} 
To understand how industry-level shifts in hedging demand lead to a migration of risk to the banking sector, we next present summary statistics on bank-firm relationships in derivatives usage, both overall and across industries. Given the over-the-counter (OTC) structure of the derivatives market, we expect that existing trading relationships between banks and firms, which are persistent in the short run at least, are an important transmission channel, similar to the findings on the role of credit relationships (e.g., Petersen and Rajan 1995; Chodorow-Reich 2013). The basic idea is that if search frictions in OTC markets, potentially related to asymmetric information problems, persist, then the existing patterns of trading relationships will determine the migration of risk and the scope for its intermediation through banks.

Table 2: Derivatives Market Participation and Structure by Industry

\begin{tabular}{lcccc}
\hline Sector & $\begin{array}{c}\text { \# Firms } \\
(1)\end{array}$ & $\begin{array}{c}\text { \# Banks } \\
(2)\end{array}$ & $\begin{array}{c}\text { \# Firms/\# Banks } \\
(3)\end{array}$ & $\begin{array}{c}\text { Bank Concentration } \\
(4)\end{array}$ \\
\hline Communication Services & 40 & 6 & 5.67 & 0.73 \\
Consumer Discretionary & 221 & 11 & 20.73 & 0.24 \\
Consumer Staples & 143 & 8 & 16.50 & 0.44 \\
Energy & 46 & 4 & 10.25 & 0.50 \\
Financials & 3457 & 62 & 53.31 & 0.35 \\
Health Care & 103 & 8 & 14.75 & 0.91 \\
Industrials & 380 & 12 & 31.58 & 0.38 \\
Information Technology & 139 & 8 & 15.88 & 0.90 \\
Materials & 165 & 9 & 18.33 & 0.29 \\
Utilities & 57 & 5 & 9.00 & 0.44 \\
NA & 4128 & 28 & 138.64 & 0.91 \\
\hline
\end{tabular}

Notes: The table shows statistics on market participation and banking concentration. Bank Concentration is the industry-level Herfindhal Index based on gross notional GBP derivatives v alues. All information refers to the pre-Brexitannouncement period (October 10, 2015, through February 22, 2016). Firms are grouped into industries following the S\&P two-digit Global Industry Classification Standard (GICS). Sources: Supervisory transaction-level derivatives available under European Markets Infrastructure Regulation (EMIR) and authors' calculations.

Table 2 shows that ex ante derivatives trading in each industry (that is, in the period before the Brexit announcement) is concentrated among a relatively small number of banks. In each nonfinancial sector, there are 4 (energy) to 12 (industrials) banks supplying derivatives out of a total sample of 66 banks that we consider in our main analysis. Standard measures of within-industry banking concentration-for example, the Herfindhal Index (HHI) based on total notional values in 
the pre-announcement period-confirm the relatively high concentration for most sectors. Given the within-industry concentration of bank derivatives supply, these findings suggest that industry shocks (industry-specific shifts in demand) will have a direct effect on the subset of banks that serve those industries.

Across an individual bank's derivatives book, different net GBP positions resulting from trades with individual firms may cancel out each other (for example, if a bank provides contracts to firms from sectors with opposite net hedging demand), thereby reducing the bank's overall net derivatives exposure and the resulting foreign exchange risk. ${ }^{18}$ Thus, how industry-specific demand shocks affect a bank's derivatives exposure, in addition to patterns of trading relationships, depends crucially on the direction and size of the shock and the relative importance of the affected industry in the bank's total derivatives book, as well as on the correlation of industry shocks and the bank's cross-industry exposure.

Table 3 reports summary statistics on the structure of banks' GBP derivatives and credit books. Importantly, the table shows that not only do industries concentrate their exchange rate hedging toward select banks, but also banks concentrate their derivatives (GBP forwards) supply toward firms from relatively few industries, as indicated by a high Herfindahl Index of industry concentration. ${ }^{19}$ In fact, the table also shows that banks' high industry concentration is not only present in their derivatives books, it is also a feature of their credit books (although the mean HHI is somewhat smaller for the credit books, with a value of 0.67 compared with 0.81 for the derivatives books). Moreover, by merging firms in the credit and derivatives data, we also find a high correlation (mean of 0.82 ) between the industry shares in a bank's derivatives book (based on gross notional shares) and its credit book (based on committed exposure shares). Thus, banks specialize in serving clients in the same industries in both their credit and derivatives businesses, suggesting that the derivativesbook concentration is part of a broader business model and - at least in the short run — given for a

\footnotetext{
${ }^{18}$ In this paper, we focus on the direct exposure to foreign exchange risk by means of the described risk migration. Indirect exposure may exist when, for instance, a bank maintains a lending relationship with a firm whose business is tied to exchange rate volatility but chooses to leave the risk unhedged. We discuss the role of banks' on-balance-sheet exposure below.

${ }^{19}$ We measure industry concentration in the derivatives client portfolio based on total notional value in the preannouncement period. That being said, concentration measures based on short and long positions are highly correlated.
} 
bank. ${ }^{20}$ As a result of the high industry concentration, when a bank faces a skewed client demand for, say, long contracts due to its ex ante industry concentration, it may find that this demand for long contracts is not cancelled out by a corresponding increase in demand for short contracts from other industries. In such a case, the bank faces a demand shift for net GBP positions, leading to a migration of risk that may not be fully intermediated across the bank's entire derivatives book. In this case, the foreign exchange risk is absorbed by the bank.

Table 3: Structure of Banks’ GBP Derivatives Book and Credit Book

\begin{tabular}{|c|c|c|c|c|c|c|c|}
\hline & Mean & St. Dev. & p10 & p25 & $\mathrm{p} 50$ & p75 & p90 \\
\hline \multicolumn{8}{|l|}{ Industry Concentrations } \\
\hline Industry Concentration (HHI) in Derivatives Book & 0.81 & 0.22 & 0.50 & 0.58 & 0.95 & 1.00 & 1.00 \\
\hline Industry Concentration (HHI) in Credit Book & 0.67 & 0.15 & 0.50 & 0.57 & 0.66 & 0.77 & 0.87 \\
\hline Correlation of Industry Shares in Credit and Derivatives Books & 0.82 & 0.30 & 0.38 & 0.74 & 0.96 & 0.99 & 1.00 \\
\hline Industry Exposure (Instrument) & 0.83 & 4.07 & -0.68 & -0.01 & 0.00 & 0.08 & 1.32 \\
\hline \multicolumn{8}{|l|}{ Overlap of Derivatives Book and Credit Book } \\
\hline Number of Derivatives Clients that are Borrowers (\%) & 69.26 & 27.61 & 33.33 & 50.00 & 67.84 & 100.00 & 100.00 \\
\hline Notional Value with Derivatives Clients that are Borrowers (\%) & 81.04 & 25.88 & 50.00 & 60.00 & 95.05 & 100.00 & 100.00 \\
\hline Number of Borrowers that are Derivatives Clients (\%) & 4.76 & 2.80 & 0.00 & 2.83 & 4.52 & 6.45 & 8.70 \\
\hline Credit Exposure of Borrowers that are Derivatives Clients (\%) & 14.44 & 20.18 & 0.70 & 1.63 & 7.09 & 14.42 & 44.84 \\
\hline
\end{tabular}

Notes: This table shows summary statistics of the credit and GBP derivatives books structure for the 66 banks in the sample of Table 9. Each observation corresponds to one bank. Industry concentrations (HHI) and shares are based on two-digit GICS industries and are computed for a bank's GBP derivatives book based on gross notional values during the pre-announcement period (October 10, 2015, through February 22, 2016), as well for the committed exposures as of 2015:Q4 recorded in the credit register. Sources: Supervisory transaction-level derivatives available under European Markets Infrastructure Regulation (EMIR), German credit register, and authors' calculations.

Consistent with such risk migration, Figure 5 shows that individual banks' post-Brexit exposure to the pound in the run-up to the Brexit referendum increased, resembling cross-industry patterns. More specifically, the fi gure shows different percentiles of the cross-sectional di stributions of banks' net long GBP exposure (as a percentage of book equity value) before the Brexit referendum. (We report banks' exposures as net long positions.) The figure highlights sizable and growing

\footnotetext{
${ }^{20}$ In fact, Table 3 also shows that, on average, a bank contracts 81 percent of its gross notional value with clients that are also borrowers in its lending portfolio, and 25 percent of all derivatives clients seek GBP derivatives and credit from the same bank. As expected, however, the number of credit borrowers that also appear in our GBP derivatives data is relatively small, suggesting that the majority of firms are not exposed to foreign exchange risk directly. The value-weighted share of those borrowers with derivatives usage is considerably higher, indicating that overall, derivatives users are larger firms.
} 
Figure 5: Bank Heterogeneity in Net Long Exposure to Post-Brexit GBP Value

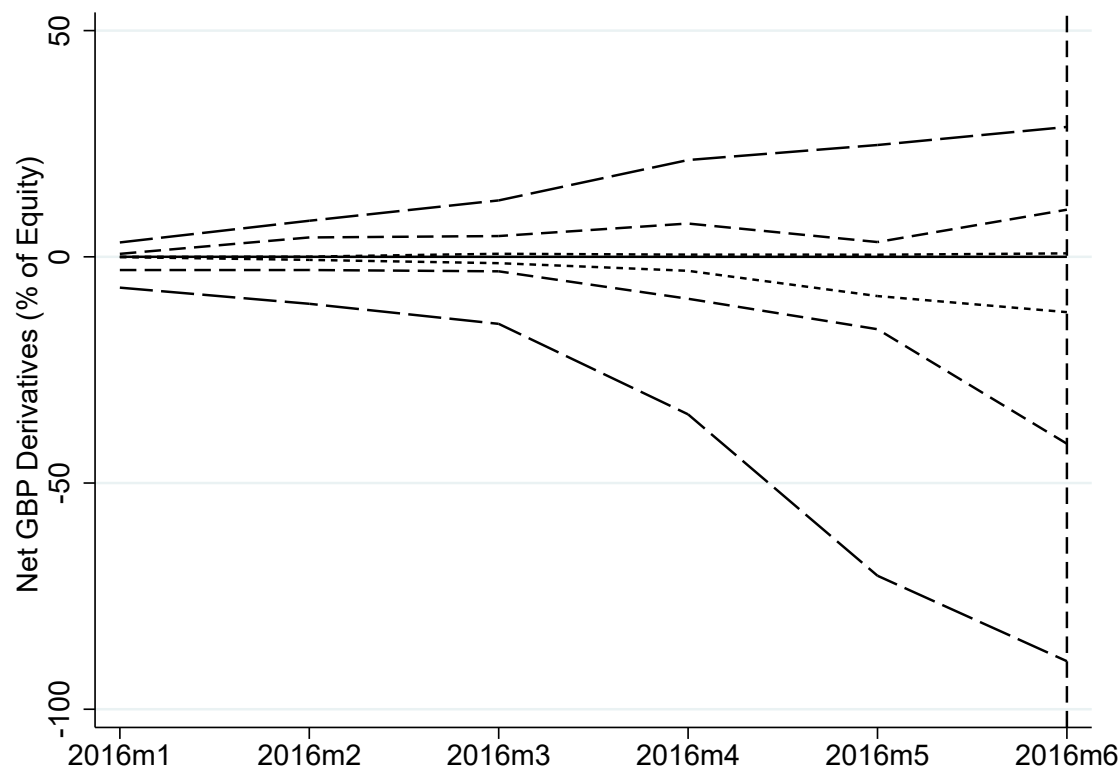

Notes: This figure shows the cross-sectional distribution of banks' cumulative net long GBP derivatives positions with maturity dates after the Brexit referendum of June 23, 2016. Net refers to the difference between exposure from long GBP derivatives positions and short GBP derivatives positions. The vertical line indicates the Brexit referendum on June 23, 2016. Long-dashed lines refer to the 5th and 95th percentiles, dashed lines to the 10th and 90th percentiles, and dotted lines to the 25th and 75th percentiles. The data points for $2016 \mathrm{~m} 6$ include only contracts initiated before the Brexit referendum. Sources: Supervisory transaction-level derivatives available under European Markets Infrastructure Regulation (EMIR) and authors' calculations.

heterogeneity in banks' net derivatives exposure to the post-Brexit value of the pound. ${ }^{21}$ Some banks increased their net short position (in the figure, negative values), while other banks increased their net long position (in the figure, positive values) as the Brexit referendum date approached. In fact, just before the Brexit referendum, about 20 percent of the banks (those in the top and bottom 10th percentiles) had built up a net GBP derivatives exposure that was larger than about 15 percent of their equity value (in absolute terms). On the other hand, about 50 percent of the banks (those between the 25th and 75th percentiles) had built up a relatively small net GBP derivatives

\footnotetext{
${ }^{21}$ Appendix Figure A4 shows that the German banking system, in aggregate, had a nonzero net GBP forward position, which increased before the Brexit referendum date.
} 
exposure; it was less than 6 percent of their equity (in absolute values). ${ }^{22}$ Summary statistics on banks' (post-Brexit) net long GBP derivatives exposure on the day of the referendum are reported in Table 4.

Table 4: Bank-Level Summary Statistics

\begin{tabular}{lccccccc}
\hline & Mean & St. Dev. & p10 & p25 & p50 & p75 & p90 \\
\hline GBP Exposure Before Brexit Referendum & & & & & & & \\
Net GBP Derivatives (\% of Equity) & -10.46 & 49.436 & -39.70 & -7.77 & -0.01 & 0.77 & 19.65 \\
Net GBP Assets (\% of Equity) & 15.24 & 45.01 & -4.18 & -0.05 & 0.02 & 3.58 & 70.28 \\
& & & & & & & \\
GBP Losses After Brexit Referendum & & & & & & & \\
GBP Derivatives Loss (\% of Equity) & -0.49 & 6.06 & -4.52 & -0.61 & -0.00 & 0.11 & 1.71 \\
GBP Total Loss (\% of Equity) & 1.90 & 7.74 & -2.52 & -0.29 & 0.00 & 0.38 & 13.53 \\
& & & & & & & \\
Size and Capital & & & & & & & \\
Assets (EUR billion) & 71.81 & 200.52 & 2.99 & 5.51 & 11.03 & 43.67 & 155.33 \\
Log (Assets) & 23.57 & 1.56 & 21.82 & 22.43 & 23.12 & 24.50 & 25.77 \\
Equity (\% of Assets) & 5.44 & 2.26 & 3.12 & 4.10 & 5.21 & 6.09 & 7.98 \\
\hline
\end{tabular}

Notes: This table shows summary statistics for the 66 banks in the sample of Table 9. Each observation corresponds to one bank. Balance sheet positions are as at May 2016. Net GBP Derivatives refers to a bank's net long GBP derivatives position. Net GBP Assets is the difference between (on-balance-sheet) GBP assets and GBP liabilities. Derivatives exposures and losses are computed for contracts initiated during the period from the Brexit referendum announcement on February 22, 2016, through June 23, 2016, the actual day of the referendum. Moreover, only contracts that mature after the Brexit referendum date, that is, those that introduce exposure to the post-Brexit value of the GBP, are considered. Derivatives losses are based on contract-level marked-to-market valuation at maturity date. Sources: Supervisory transaction-level derivatives available under European Markets Infrastructure Regulation (EMIR), banks' external positions (AUSTA), balance sheet statistic (BISTA), and authors' calculations.

\subsection{2 (Re)Allocation of Migrated Foreign Exchange Risk among Banks}

We next study the risk migration and intermediation, as well as the resulting net derivatives exposure, of banks in response to heterogeneous industry-level demand shifts, including the reallocation of risk through the interbank forward market. To isolate the effects of demand shifts, we exploit the heterogeneity in industry concentration in a bank's derivatives book, enabling us to exploit shifts in industry-specific hedging demand before the Brexit referendum, which are exogenous to an

\footnotetext{
${ }^{22}$ In Appendix Figure A5, we show that the heterogeneity in net GBP derivatives exposure is not driven by end-ofquarter regulatory arbitrage (e.g., Du et al. 2018; Abbassi and Bräuning 2020), as we find similar patterns when we restrict the data to forward contracts that mature after the referendum but before June 30, 2016 (that is, the end of the quarter).
} 
individual bank, and devise an instrument for a bank's net derivatives position. More precisely, together with an exogenous industry-exposure differential across banks, common industry shocks allow us to identify exogenous variation in banks' net GBP derivatives positions, and ultimately in the related derivatives losses, as we will show in the next section. The idea underlying the construction of our instrument closely follows the concept of a Bartik instrument (e.g., GoldsmithPinkham et al. 2018; Borusyak et al. 2018). Though initially developed in the context of labor market research, these Bartik-type, or shift-share, instruments have been employed increasingly in empirical macro-financial research studies (e.g., Greenstone et al. 2020). Formally, we compute the bank's exposure to net short industries as

$$
\text { Industry Exposure }_{i}=\sum_{s} w_{i, s} \times \text { Industry Net Short GBP Exposure }{ }_{s},
$$

where Industry Net Short GBP Exposure ${ }_{s}$ is industry $s$ 's net short exposure to the post-Brexit pound value computed for all contracts initiated after the announcement date and before the referendum date and maturing after the referendum date. The predetermined weight $w_{i, s}$ in our baseline measure is computed as bank $i$ 's share in industry $s$ 's short positions minus bank $i$ 's share in industry $s$ 's long positions, both measured during the pre-announcement period. Thus, our Bartik-like instrument measures how much the bank is exposed to industry-specific skewed hedging demand, taking into account directional (short versus long) trading relationships between a bank and a sector during the pre-sample period. As with our bank's net GBP Derivatives Exposure variable, we normalize our Bartik-like instrument with the bank's equity value.

We argue that banks, which ex ante (before the announcement) had derivatives books con-centrated toward industries that ex post (after the announcement) built up large net GBP short positions, were more likely to absorb some of the foreign exchange risk and build up net GBP long positions; that is, they went in the opposite directions of their clients and did not fully intermediate the migrated risk. In Table 5, we report means of banks' net GBP derivatives exposure and prices (forward premia), conditional on high and low values of our Bartik-like instrument. The results are consistent with the notion that banks with large ex ante exposure to net GBP short (long) industries 
Table 5: Banks' Net GBP Position and Forward Premium by Industry Exposure

\begin{tabular}{lcc}
\hline & \multicolumn{2}{c}{ High Derivative Exposure (Bartik) to } \\
& Net Long Industry & Net Short Industry \\
\hline Net GBP Derivatives (\% of Equity) & -51.97 & 0.88 \\
Forward Premium (bps) & 16.50 & 52.67 \\
Derivative Loss (\% of Equity) & -4.64 & 4.08 \\
\hline
\end{tabular}

Notes: This table reports the mean of banks' net long GBP position before the Brexit referendum, the mean of banks' value-weighted mean GBP forward premium based on all contracts that mature after the Brexit referendum, and the post-referendum derivatives losses. Means are reported for banks with a high pre-sample exposure to net short industries (that is, Industry Exposure $>$ p90) and for banks with a high pre-sample exposure to net long industries (Industry Exposure $<\mathrm{p} 10)$. Pre-sample exposures are based on a bank's GBP derivatives book using gross notional values during the pre-announcement period (October 10, 2015, through February 22, 2016). Sources: Supervisory transaction-level derivatives available under European Markets Infrastructure Regulation (EMIR), banks' external positions (AUSTA), balance sheet statistic (BISTA), and authors' calculations.

tended to be net long (short) in the pound before the referendum date. In addition, Table 5 reveals substantial price heterogeneity, suggesting that - in line with our model's prediction-forward prices adjust to make banks hold the foreign exchange risk. In fact, banks with high exposure to net GBP short industries on average achieved higher forward rates on their derivatives books compared with banks with exposure to net GBP long industries. ${ }^{23}$ (Table 5 also reports post-Brexit derivatives losses, which we will discuss in the following section.)

We next show results from regression analysis to provide more detailed evidence on the relationship between a bank's ex ante industry exposure and its net GBP derivatives position (quantities) and forward premium (prices). Our regression equation is given by

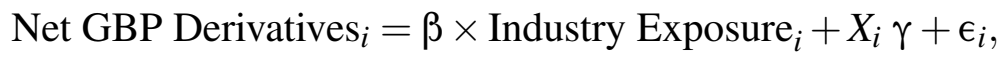

where Net GBP Derivatives is a bank's net long GBP derivatives (as a percentage of equity) position at the Brexit referendum date, that is, the exposure to the post-Brexit depreciation of the pound. In addition to using the exposure measure, we use the forward premium as the dependent variable. $X_{i}$ is a vector of bank controls. To highlight the effects on the banks with meaningful net GBP

\footnotetext{
${ }^{23}$ Recall that our forward rate is defined as pound per euro. Thus, a bank that buys pounds would prefer a higher rate, while a bank that sells pounds would prefer a lower rate.
} 
exposure (about 50 percent of all banks have a net exposure greater than 5 percent of equity), we employ weighted regressions in which we use banks' absolute net GBP exposure as a percentage of equity as weights.

Table 6, column (1), shows that a bank's post-Brexit net long GBP exposure is strongly related to the pre-sample industry concentration in its derivatives book. More specifically, the positive coefficient estimate shows that, after we control for other bank characteristics, banks with exposure to net short (long) industries tend to be net long (short) themselves, which resembles the unconditional summary statistics discussed above.

Table 6: Net Long GBP Derivatives and Forward Premia at the Bank Level

\begin{tabular}{|c|c|c|c|c|}
\hline & \multicolumn{4}{|c|}{ Dependent Variable: } \\
\hline & \multicolumn{2}{|c|}{ Net GBP Derivatives } & \multicolumn{2}{|c|}{ Forward Premium } \\
\hline & (1) & (2) & (3) & (4) \\
\hline Industry Exposure & $\begin{array}{c}14.21 * \\
(7.57)\end{array}$ & $\begin{array}{c}9.79 * * * \\
(3.66)\end{array}$ & $\begin{array}{l}5.90 * \\
(3.21)\end{array}$ & \\
\hline Net GBP Derivatives & & & & $\begin{array}{c}0.60 * * \\
(0.26)\end{array}$ \\
\hline Net GBP Assets & & $\begin{array}{c}-0.90 * * * \\
(0.33)\end{array}$ & $\begin{array}{c}0.09 \\
(0.06)\end{array}$ & $\begin{array}{c}0.63 * * \\
(0.30)\end{array}$ \\
\hline Estimation & OLS & OLS & OLS & IV \\
\hline Bank Controls & Yes & Yes & Yes & Yes \\
\hline Observations & 66 & 66 & 66 & 66 \\
\hline
\end{tabular}

Notes: This table shows the impact of a bank's ex ante industry exposure in the derivatives market on the pre-Brexit risk migration. Net GBP Derivatives is the bank's net long GBP derivatives position on the day of the Brexit referendum (as a percentage of equity). Forward Premium is the (value-weighted) mean forward premium (in basis points) associated with the bank's net long GBP derivatives position on the day of the Brexit referendum. Exchange rates are defined in pounds per euro. Industry Exposure is the Bartik-like variable that interacts a bank's pre-sample industry shares in the GBP derivatives market with industry-level net short GBP positions at the Brexit referendum. Net GBP Assets is the difference between the bank's on-balance-sheet GBP assets and GBP liabilities. Each independent variable is expressed as a percentage of equity. Bank Controls includes equity (percentage of assets) and the logarithm of total assets. Column (4) presents instrumental variable estimates based on first-stage re sults re ported in column (2). Regressions are weighted with banks' absolute values of GBP derivatives exposure. Robust standard errors are reported in parentheses. $* * * \mathrm{p}<0.01, * * \mathrm{p}<0.05,{ }^{*} \mathrm{p}<0.1$. Sources: Supervisory transaction-level derivatives available under European Markets Infrastructure Regulation (EMIR), banks' external positions (AUSTA), balance sheet statistic (BISTA), and authors' calculations. 
In addition to derivatives exposure, banks may have exposure to the pound through their regular credit and deposit (on-balance-sheet) activity, which may naturally hedge their derivatives book. For example, a bank may hedge an on-balance-sheet GBP loan by selling GBP forward, that is, by creating a matched off-balance-sheet GBP liability (short position, the promise to deliver GBP at the forward date). However, a bank may find it profitable to meet skewed client demand in the derivatives market and, as a result, reduce its on-balance-sheet position to keep the overall exposure to the pound unchanged.

We therefore include in column (2) banks' GBP net assets directly as a control variable. The positive coefficient close to 1 shows that banks that have positive net GBP assets-an on-balancesheet long exposure—-tend to have a derivatives short exposure. Importantly, however, the coefficient on our Bartik-like instrument remains positive, and its standard error decreases substantially, leading to stronger (statistical) significance. Thus, conditional on a given on-balance-sheet exposure, industry-level skewed derivatives demand prior to the Brexit referendum affected a bank's net derivatives position through its pre-sample client structure. Our point estimate indicates that a 1 standard deviation increase in the industry exposure is associated with a sizable increase in net GBP derivatives exposure of 38.3 percentage points $(9.79 * 3.91)$.

In columns (3) and (4), we provide more evidence of price adjustments in the forward market as the key mechanism through which the risk reallocation works. In particular, column (3) shows a strong positive relationship between our Bartik-like variable and the forward premium, indicating that banks that have a GBP derivatives book concentrated toward industries with large net derivatives positions obtain more favorable forward premia. Recall that a bank that is net long in the pound benefits from a higher forward premium, whereas a bank that is net short benefits from a lower forward premium. This result is consistent with our model's prediction that prices increase in a way that makes banks willing to absorb the additional risk. In column (4), we present the same results using a more structural model, where we regress the forward premium on the bank's net GBP exposure instrumented with our Bartik-like variable. The results become stronger in significance and indicate that for a 1 standard deviation increase in net long exposure, banks are remunerated 
with a forward premium that is 23 basis points greater $(0.63 * 37.86)$, which is quite significant economically.

The results in columns (3) and (4) are based on a (volume-weighted) mean forward rate of all forward contracts of a given bank, including forward sales and purchases. In unreported results, we look at buy and sell rates separately and find that while banks with large net long (short) exposure obtain better (worse) rates compared with other banks' forward purchases (sales), they also pay relatively higher (lower) prices on their short (long) positions, which reduces their overall net long (short) GBP position.

Table 7: Interbank Reallocation of Foreign Exchange Risk at the Bank Level

\begin{tabular}{lccc}
\hline & \multicolumn{3}{c}{ Dependent Variable: } \\
\cline { 2 - 4 } & $\begin{array}{c}\text { Net GBP Derivatives } \\
\text { (Nonbank) } \\
\end{array}$ & $\begin{array}{c}\text { Net GBP Derivatives } \\
(1)\end{array}$ & $\begin{array}{c}\Delta \text { Forward Premium } \\
\text { (Nonbank-Interbank) }\end{array}$ \\
\hline Industry Exposure & $10.32^{* * *}$ & $(2)$ & $(3)$ \\
Net GBP Derivatives (Nonbank) & $(1.73)$ & $-0.87^{* * *}$ & \\
Net GBP Derivatives (Interbank) & & $(0.17)$ & $2.85^{* * *}$ \\
Net GBP Assets & & & $(0.57)$ \\
& $-0.94 * * *$ & $-0.84^{* * *}$ & $0.79^{* *}$ \\
Estimation & $(0.13)$ & $(0.25)$ & $(0.38)$ \\
Bank Controls & & & 3 SLS \\
Observations & 3 SLS & $3 S L S$ & Yes \\
\hline
\end{tabular}

Notes: This table shows the intermediation of foreign exchange risk in the interbank market using 3SLS estimation of the system of equations in columns (1) through (3). Net GBP Derivatives is the bank's net long GBP derivatives position on the day of the Brexit referendum (as a percentage of equity). Forward Premium is the (value-weighted) mean forward premium (in basis points) associated with the bank's net long GBP derivatives position on the day of the Brexit referendum. Exchange rates are defined in pounds per euro. Net GBP Derivatives and Forward Premium are computed for nonbank and bank counterparties separately. $\Delta$ Forward Premium is the spread between the forward premium on nonbank and interbank trades, expressed as a percentage of the bank's mean forward premium. Industry Exposure is the Bartik-like variable that interacts a bank's pre-sample industry shares in the GBP derivatives market with industry-level net short GBP positions on the date of the Brexit referendum. Net GBP Assets is the difference between the bank's on-balance-sheet GBP assets and GBP liabilities. Each independent variable is expressed as a percentage of equity. Bank Controls includes equity (percentage of assets) and the logarithm of total assets. Regressions are weighted with banks' absolute values of GBP derivatives exposure. Robust standard errors are reported in parentheses. *** $\mathrm{p}<0.01$, ** $\mathrm{p}<0.05, * \mathrm{p}<0.1$. Sources: Supervisory transaction-level derivatives available under European Markets Infrastructure Regulation (EMIR), banks' external positions (AUSTA), balance sheet statistic (BISTA), and authors' calculations. 
Our analysis so far documents a migration of foreign exchange risk from (nonbank) firms to banks in the period before the Brexit referendum date that can be explained by banks' heterogeneous ex ante industry exposure. We show that some banks maintained a substantial share of this migrated risk on their own books and did not intermediate it to other agents in the economy. Our analysis also shows that, overall, banks with larger exposures were compensated for holding the net derivatives exposure. One question that arises in this context is why banks left these net positions unhedged when they could have turned to the interbank market for full risk intermediation.

To address this important question, we present, in Table 7, results of a three-stage least squares (3SLS) estimation of the system of equations of banks' net GBP derivatives positions, separately vis-à-vis nonbank and bank counterparties, as well as forward premia differentials between nonbank and interbank positions, respectively. (That is, columns [1] through [3] are jointly estimated using industry exposure as the fundamental instrument.) In column (1), we show that our Bartik-like industry-exposure variable is significantly related to net (long) GBP derivatives positions vis-à-vis the nonbank sector. The results suggest that banks serving industries with net demand for short contracts tended to build up net long GBP positions with nonbanks before the Brexit referendum. Column (2) shows that a bank's interbank net GBP positions are strongly negatively related to its net GBP position vis-à-vis nonbank counterparties (instrumented with the industry exposure; see column [1]). The point estimate of close to, but below, the value of 1 suggests that banks offset a large share (87 percent)—but not all—of their nonzero net derivatives positions that had migrated from nonbank counterparties into the interbank market.

Column (3) shows results for the spread between the (volume-weighted) forward premium on nonbank derivatives positions versus interbank derivatives positions. If the spread widens, the forward premium on nonbank positions increases relative to the forward premium on interbank positions. Recalling that the exchange rate is expressed in GBP per EUR, a bank prefers a higher forward premium on long positions and a lower forward premium on short positions. The results from all three columns together suggest that a bank that enters a short position due to high ex ante (long) industry exposure (column [1]) will intermediate part of the long exposure by offsetting short 
positions in the interbank market (column [2]), resulting in a higher interbank forward premium on the short positions (relative to what is earned on the long nonbank positions), thereby reducing the spread. In other words, we again find that the bank obtains compensation for holding exchange risk migrated from the nonbank sector through higher spreads, whereas hedging more of this risk in the interbank market reduces the spread. The coefficient estimate suggests that for a 1 percentage point higher interbank (short) position — a reduction of the value of Net GBP Derivatives (Interbank)—the spread decreases a sizable, 2.85 percent. This result is also consistent with the notion that banks may refrain from full risk intermediation because their marginal cost of hedging in the interbank market exceeds the expected profit from the provision of the foreign exchange insurance to the nonbank counterparties.

While price adjustments are informative about why some banks choose not to fully intermediate the migrated exchange risk through the interbank market, we do not analyze the fundamental reasons behind price increases that prevent a perfect risk intermediation through the interbank market (that is, that limit the supply of interbank hedges). In other words, we show that interbank supply is not perfectly elastic, taking the reasons as given. In this context, for example, regulation has been shown to affect bank intermediation in foreign exchange derivatives markets to such an extent that deviations from covered interest parity can occur (e.g., Du et al. 2018; Abbassi and Bräuning 2020).

\subsection{Systemic Implications of Foreign Exchange Risk Migration}

\subsubsection{Banks' Response to the Brexit Referendum Outcome}

In the next step, we study whether migrated and imperfectly intermediated foreign exchange risk affects banks' credit supply once the exchange rate risk materializes (our third hypothesis). In particular, banks that increased their net exposure to the post-Brexit value of the pound through their derivatives book before the Brexit referendum suffered losses or gains after the Brexit referendum depending on whether they were net short or long in the pound, which depreciated substantially against the euro in the period immediately after the Brexit vote result became public. For a bank that is capital constrained, such a shock may induce an equity loss resulting from a net long position 
in the pound, with potential implications for its lending.

To study this relationship, we use the granularity of our data set and construct a measure of the bank's GBP derivatives losses based on individual forward contracts. In particular, we compute the marked-to-market value at maturity for each contract that a bank sold or bought between the Brexit referendum announcement and the actual referendum and that matured after the referendum date. Formally, we calculate the bank's GBP derivatives loss as

$$
\text { GBP Derivatives } \operatorname{Loss}_{i}=-\sum_{\substack{c \neq i \\ m>\text { Brexit } \\ t<\text { Brexit }}}\left(S_{m}-X_{i, c, t, m}^{f}\right) F_{i, c, t, m}^{s}+\left(X_{i, c, t, m}^{f}-S_{m}\right) F_{i, c, t, m}^{b},
$$

where $X_{i, c, t, m}^{f}$ is the agreed forward rate of a contract initiated at time $t$ (between the Brexit announcement and referendum date) between bank $i$ and counterparty $c$ that matures at time $m$ after the Brexit referendum. $S_{m}$ is the spot rate prevailing at the maturity date. Both spot rates are in GBP per EUR. Thus, a marked-to-market loss from a contract in which the bank buys pounds forward occurs if $X_{i, c, t, m}^{f}<S_{m}$, that is, if the pound has depreciated at maturity relative to the contractually agreed exchange rate. The opposite holds for contracts in which the bank agreed to sell pounds forward. Importantly, because of the way we construct these post-Brexit derivatives losses, they are predetermined by the exposure entered before the Brexit referendum date and the aggregate spot exchange rate movement after the Brexit referendum date (which is exogenous to the bank). ${ }^{24}$ We normalize the GBP Derivatives Loss with the bank's equity value as of the end of May 2016. Summary statistics that characterize the distribution of losses are shown in Table 4.

Our second measure of GBP losses takes into account marked-to-market gains (or losses) from on-balance-sheet positions denominated in British pounds in addition to derivatives losses. Controlling for on-balance-sheet gains and losses is important because banks with large net GBP derivatives exposure (either short or long) could have entered those positions before the Brexit

\footnotetext{
${ }^{24}$ Figure A2 shows that while the euro appreciated relative to the pound after the Brexit referendum, the euro's value did not change relative to other major currencies. As a result, a bank's losses from a GBP long exposure could not be offset by nonzero exposure in other currencies.
} 
referendum to hedge their on-balance-sheet exposure (see Table 6). Therefore, we compute

$$
\text { GBP Total } \text { Loss }_{i}=\text { GBP Derivatives Loss } i-\Delta S \times \text { Net GBP Assets }_{i},
$$

where GBP Net Assets is the difference between the bank's on-balance-sheet assets and liabilities in May 2016, and $\Delta S$ is the average percentage change in the GBP spot exchange rate of about -12 percent in the aftermath of the Brexit referendum (mean during the third quarter of 2008). Unlike with the derivatives losses, for which we have detailed contract-level information, we impose this marked-to-market loss for the on-balance-sheet exposures, for which we do not observe the precise maturity date. However, because most on-balance-sheet net GBP assets are of longer-term maturity (for example, loans), the estimated on-balance-sheet loss (and gain) of net pound assets is likely to be unrealized. Thus, this variable builds in a forward-looking component of losses that may occur once the book value has to be written off. As with the GBP Derivatives Loss, we normalize GBP Total Loss with the bank's equity value as of the end of May 2016.

We use these two GBP loss measures in a regression framework to study the link between realized foreign exchange risk and credit. In the first set of results, we focus on identification of the supply effect before moving to more aggregate measures of credit, which represent an interplay between supply and demand shocks. To isolate the supply effect, we use bank-firm-level credit exposure data, which allow us to control for concurrent demand effects. Our setup is similar to a standard difference-in-differences approach used in the banking literature (Khwaja and Mian 2008). In particular, we model the percentage credit growth (difference in logarithm of committed exposure) at the bank-firm level between 2016:Q2 and 2016:Q3. ${ }^{25}$ Our key explanatory variable is a bank's loss resulting from its derivatives exposure to the post-referendum GBP value, and we control for borrower fixed effects in all regressions to account for demand heterogeneity. Thus, we compare credit growth by banks that bear different derivatives losses to the same borrower firm

\footnotetext{
${ }^{25}$ The exposure in 2016:Q2 was only marginally affected by the outcome of the Brexit referendum on June 23, 2016, given that in Q2 there were only five business days after the referendum. While in principle there is still a chance that the 2016:Q2 credit exposure was affected by the referendum outcome, we find very similar results if we look at the change in credit between 2016:Q1 and 2016:Q3.
} 
(while also netting out borrower-specific time trends). Formally, our baseline regression equation is given by

$$
\Delta \text { Credit }_{i, j}=\beta \cdot \text { GBP Derivatives } \operatorname{Loss}_{i}+X_{i} \gamma+\alpha_{j}+\epsilon_{i, j}
$$

where $\alpha_{j}$ is borrower j's fixed effect, and $X_{i}$ is a vector of bank-specific control variables that include balance-sheet variables and related supervisory data. Our selection of controls is guided by balance-check tests (Figure Appendix A6). We use both the GBP derivatives loss and the GBP total loss (derivatives and on-balance-sheet gains/losses). Note that there is only one time period in the regression because we are studying the difference in differences of credit growth between 2016:Q2 and 2016:Q3. Our inference is based on robust standard errors clustered at the bank level.

Figure 6: Scatter of GBP Derivatives Losses against Industry Exposure

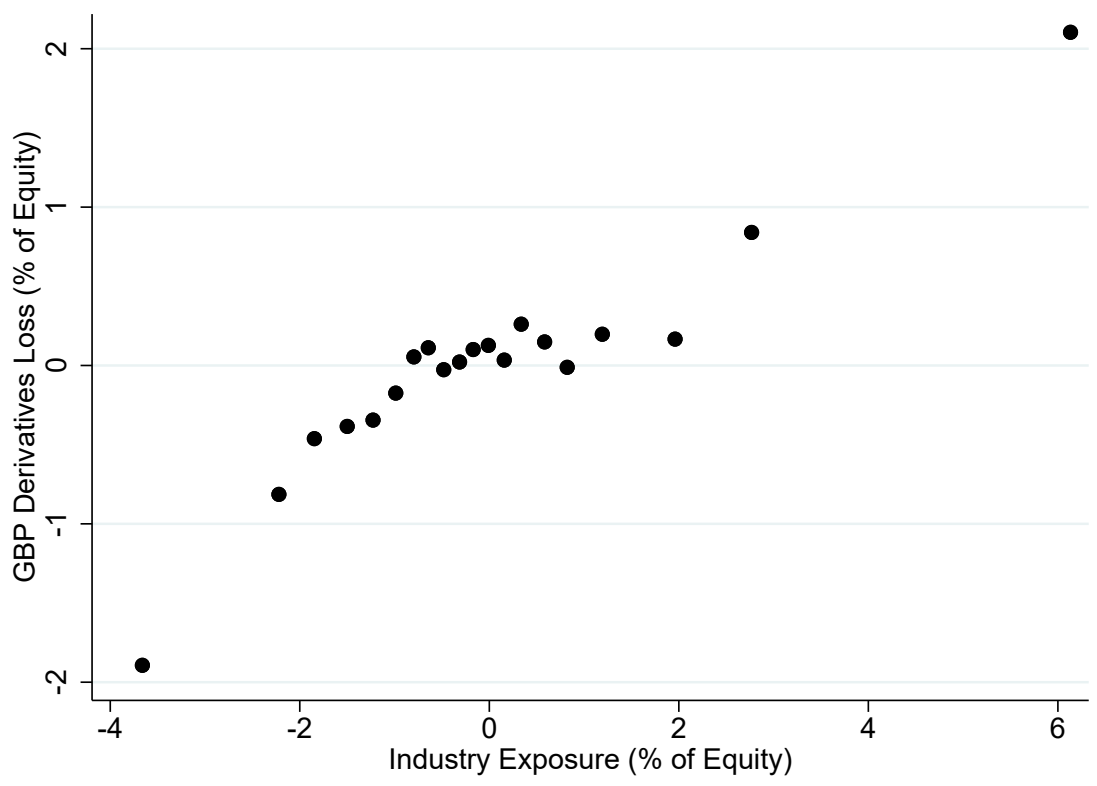

Notes: This figure shows a bin scatter of post-Brexit derivatives losses against the industry exposure (instrument). Both variables are orthogonalized against the variables in our baseline specification in Table 8, column (2). Each scatter dot refers to a group of (at least) three banks, hence the 20 quantiles. Sources: Supervisory transaction-level derivatives available under European Markets Infrastructure Regulation (EMIR), banks' external positions (AUSTA), balance sheet statistic (BISTA), German credit register, and authors' calculations.

In our core results, we instrument a bank's foreign exchange derivatives loss with the exposure measure based on the bank's ex ante (that is, pre-Brexit-announcement) industry shares and cross- 
industry variation in net post-Brexit positions. Instrumenting our derivatives loss variables alleviates concerns that our derivatives-loss measure could correlate with losses from other lines of business (credit, securities trading, etc.) that could lead to a reduction in loan supply (e.g., Abbassi et al. 2016). We already showed that our Bartik-like industry-exposure measure is strongly positively correlated with the bank's net exposure. In Figure 6, we present a bin-scatter plot that illustrates the close relationship between banks' industry exposure and post-Brexit GBP derivatives losses ( that is, a weighted sum of exposures).

Table 8: Credit-Growth Regressions at the Bank-Firm Level

\begin{tabular}{lcccc}
\hline & \multicolumn{3}{c}{ Dep. Variable: Credit Growth } \\
\cline { 2 - 4 } & $(1)$ & $(2)$ & $(3)$ & $(4)$ \\
\cline { 2 - 4 } GBP Derivatives Loss & $-0.28^{*}$ & $-0.73^{* *}$ & \\
GBP Total Loss & $(0.16)$ & $(0.31)$ & $-0.74 * *$ & $-1.64 * * *$ \\
GBP Total Loss * Equity & & & $(0.33)$ & $(0.64)$ \\
& & & & $0.24 *$ \\
Net GBP Assets & & & & $(0.14)$ \\
& $-0.04 * *$ & $-0.04^{* *}$ & \\
Estimation & $(0.02)$ & $(0.02)$ & \\
Bank Controls & & & & \\
Borrower Fixed Effects & OLS & IV & IV \\
Observations & Yes & Yes & Yes & Yes \\
& 59,829 & 59,829 & 59,829 & Yes \\
\hline
\end{tabular}

Notes: This table shows the post-Brexit referendum credit growth at the bank-firm level depending on a bank's GBP derivatives losses and its equity ratio. The dependent variable Credit Growth is a bank's percentage change in credit outstanding to a given borrower between 2016:Q2 and 2016:Q3. The independent variable GBP Derivatives Loss is the marked-to-market loss in the post-Brexit period from a bank's GBP derivatives positions entered before the Brexit referendum (as a percentage of equity). The independent variable GBP Total Loss adjusts the value of GBP Derivatives Loss by the estimated marked-to-market gain/loss from on-balance-sheet GBP exposure (as a percentage of equity). GBP Net Assets is the difference between the bank's on-balance-sheet GBP assets and liabilities (as a percentage of equity). Bank Controls includes the equity-to-assets ratio, the logarithm of total assets, the share of gross notional GBP derivatives with UK-based counterparties during the pre-announcement period, and the share of credit committed to UK borrowers. All balance sheet variables are predetermined using May 2016 values. In column (4), all control variables are also interacted with the equity-to-assets ratio, but coefficients are not reported in the table. Robust standard errors are clustered at the bank level and reported in parentheses. ${ }^{* * *} \mathrm{p}<0.01,{ }^{*} \mathrm{p}<0.05,{ }^{*} \mathrm{p}<0.1$. Sources: Supervisory transaction-level derivatives available under European Markets Infrastructure Regulation (EMIR), banks' external positions (AUSTA), balance sheet statistic (BISTA), German credit register, and authors' calculations. 
Table 8 presents the estimation results. Results presented in column (1) are based on least squares estimates and suggest that a 1 percentage point increase in losses (relative to equity) from the foreign exchange derivatives business translates into a significant, one-third of a percentage point reduction of credit. To isolate the effect of foreign exchange derivatives losses on credit supply, we run extensive balance-check tests for a large set of bank characteristics, which are reported in Figure A6. Based on the results, we include bank size, equity, and the on-balance-sheet net exposure to GBP assets in all regressions. The last control is important because banks with large GBP derivatives exposure could have entered those positions before the Brexit referendum to hedge their on-balance-sheet exposure (see Table 6). In addition, we control for the (gross notional) value share contracted with UK-based counterparties, and, in a similar spirit, the value share of credit committed to UK borrowers.

Columns (2) through (4) present results from instrumental variable (IV) regressions in which the derivatives loss is instrumented with the Bartik-type industry exposure. Compared with our OLS estimate of -0.28 , we find a larger coefficient (in absolute value), with a point estimate of -0.73 , which is significant at the 5 percent level. We include the same set of controls as in column (1) to improve efficiency. Analysis of the first-stage results supports the validity of our IV approach. For example, we can reject the hypothesis of under-identification at the 5 percent significance level with a cluster-robust Kleinbergen-Paap test statistic of 3.598 and a positive first-stage coefficient on our Bartik-like variable that is significant at the 5 percent level. The relationship between derivatives losses and our instrument is shown graphically in Figure 6.

In column (3), we use our second measure of a bank's losses from derivatives trading, which directly adjusts for estimated losses/gains from a bank's on-balance-sheet positions, instead of including the on-balance-sheet net position as a control. Using this adjusted derivatives-loss measure, our coefficient estimate remains quantitatively almost identical to our estimate in column (3), which is consistent with our Bartik-like variable identifying exogenous variation in derivatives losses (that is, derivatives losses uncorrelated with other bank characteristics, such as a bank's GBP credit book). The point estimate indicates that an increase in net derivatives losses (relative to equity) of 1 
percentage point leads to a 0.74 percent cutback in credit. ${ }^{26}$

Our baseline results from columns (1) through (3) establish a link between GBP forward losses and credit supply for the average bank in our sample. The economic channel hypothesized in our model section builds on the bank's equity capital as the binding constraint, such that a loss from derivatives trading, which affects a bank's equity capital, leads to a reduction in credit. Our previous coefficient estimates measure the effect of forward losses on credit for the average capitalized bank in the sample. (Table 4 shows that the average bank in our sample has an equity ratio of about 5.5 percent.) In that sense, our results are in line with our theoretical framework, in which under a capital-constraint assumption, a derivatives loss leads to a contraction in credit. ${ }^{27}$ It is noteworthy that our estimated effect of bank equity on credit is smaller than 1, suggesting an elasticity that is smaller than 1. This result is consistent with the findings in the banking literature (e.g., Berger and Bouwman 2009; Öztekin and Flannery 2012) that suggest a smooth adjustment in credit in response to an equity shortfall relative to the bank's optimal level, which is based on both regulatory and internal risk management considerations and thus typically higher than the regulatory minimum. ${ }^{28}$

In column (4), we provide further evidence on the specific economic channel by looking at heterogeneous effects that depend on the level of the capital ratio. In particular, we interact the derivatives-loss variable with bank equity to determine whether the contraction in credit in response to derivatives losses is stronger for low-equity banks. ${ }^{29}$ (For completeness, we also interact the control variables with bank equity; but to avoid cluttering, we do not report the coefficients.) The positive coefficient on the interaction term shows that, indeed, ex ante low-equity banks (measured as of May 2016, that is, before the actual referendum date) cut back credit more strongly in response to derivatives losses compared with ex ante higher-equity banks. As noted in the previous discussion, low-equity banks are supposedly closer to the regulatory minimum capital ratio, and as a result,

\footnotetext{
${ }^{26}$ We obtain a significant coefficient of -0.65 if we estimate column (3) without borrower fixed effects, confirming the exogeneity of our instrument with respect to observed and unobserved borrower-specific characteristics.

${ }^{27}$ Measuring the tightness of a bank's capital constraint is not straightforward, as both regulatory and internal (risk management) considerations could affect a bank's latent optimal capital level. We follow the standard approach and use the cross section of book equity as a proxy for the relative tightness of capital constraints.

${ }^{28}$ In unreported analysis, we find no further differential effect depending on the size of the GBP derivatives loss.

${ }^{29} \mathrm{We}$ use our Bartik-like variable and the interaction term of our Bartik-like variable with the equity ratio as instruments in the first stage.
} 
regulatory constraints become more important when the shock materializes, thus hampering banks' ability to adjust credit more smoothly. ${ }^{30}$ In economic terms, we estimate that the cutback in credit is about 0.2 percent stronger when a bank has a 1 percentage point lower equity ratio. This effect is significant at the 10 percent level and is robust to controlling for borrower fixed effects. Thus, the coefficients are identified, as before, by comparing changes in credit by different banks to the same firm in the same quarter, depending on variation in derivatives losses and equity ratios (and netting out borrower-specific time trends).

In the Appendix, we provide further evidence on the validity of our identification strategy and analyze the persistence of the identified credit effect resulting from GBP losses after the Brexit referendum. In particular, Figure A7 reports coefficient estimates on our key variable (GBP Derivatives Loss) while conducting our analysis on changes in (log) credit relative to the pre-Brexit quarter at different points in time as our dependent variable: Credit $_{i, j, t}-\mathrm{Credit}_{i, j, 0}$, with $t=-2, . ., 2$, and $t=0$, the pre-Brexit quarter, 2016:Q2 (while before we focused on regressions with $t=1$ ). The results show that credit growth before the Brexit referendum in 2016:Q2 was not significantly different for banks that experienced GBP losses in the aftermath of the Brexit referendum. Thus, we cannot reject the important parallel trends assumption required in any type of difference-in-differences study, thereby supporting the validity of our identification approach. Moreover, Appendix Figure A7 also shows that the negative impact on credit lasts for one quarter and is not distinguishable from zero after two quarters.

\subsubsection{Implications for Firm-Level Credit and Real Effects}

Next, we assess the implications of the effect of foreign exchange risk migration for the real economy. In particular, we examine whether the identified bank credit supply shock has an overall impact on firm-level credit. This is important because firms could potentially substitute a lack of credit availability from one bank with an increase in borrowing from another bank. To estimate the credit effects at the firm level, we look at the total firm-level credit growth (percentage change in

\footnotetext{
${ }^{30}$ Consistent with the leverage ratio being the binding constraint, we do not find evidence that high-derivatives-loss banks with low Tier-1 (risk-weighted) capital ratios adjusted credit more after Brexit.
} 
exposure by all creditors) between 2016:Q2 and 2016:Q3. We relate this firm-level credit growth to an indicator variable that takes the value of 1 whenever the firm had a substantial credit reliance on a bank with derivatives losses before the Brexit referendum, and 0 otherwise. ${ }^{31}$ That is, we compute for each firm $j$ the variable

$$
\text { GBP-Loss-Bank Reliance }{ }_{j}=\sum_{i} w_{i, j} \cdot \mathbb{1}\left(\text { GBP Total } \operatorname{Loss}_{i}>0\right),
$$

where $w_{i, j}=\mathrm{Credit}_{i, j} / \sum_{i} \mathrm{Credit}_{i, j}$, with $\mathrm{Credit}_{i, j}$ being the 2016:Q2 credit with bank $i$. We weight the loss dummy $\mathbb{1}\left(\right.$ GBP Total $\left.\operatorname{Loss}_{i}>0\right)$ from a firm's different creditors to account for the possibility that effects are less strong if a bank with large losses is not important to a given firm. However, our results do not depend on the weighting and are robust to other firm-level measures of exposure to loss-realizing banks (including a continuous measure).

Banks in Germany with GBP derivatives losses provide credit to a large share of firms. For example, in 2016:Q2, we observe 83,784 firms (or 18.88 percent of all firms) with outstanding credit from loss-realizing banks. Moreover, firms' borrowing from those banks accounts for 50.5 percent of all outstanding bank credit in our sample. Given the importance of loss-realizing banks, we expect that the credit shock has an impact on firm credit; that is, the firm is not able to substitute the experienced cutback in credit. Before we move to more detailed regression analysis, at a high level, Figure 7 plots firms' credit growth by creditor type to convey a sense of the unconditional pattern. In the figure, we distinguish between firms that borrow from at least one bank with GBP derivatives losses (solid line) and firms that borrow from no banks with GBP derivatives losses (dashed line, both based on 2016:Q2 credit exposure). The figure shows that for both bank types, credit growth declined after the Brexit referendum until 2016:Q4. ${ }^{32}$ However, in the quarter after the Brexit referendum, the credit growth of firms borrowing from GBP-loss-realizing banks dropped

\footnotetext{
${ }^{31}$ The notion of credit dependence is in line with the well-established presence of persistent banking relationships and switching frictions in credit markets, which, in turn, are often related to asymmetric information problems; see the discussion and literature references in Petersen and Rajan (1995) and Chodorow-Reich (2013).

${ }^{32}$ As discussed, other factors, including demand shifts, could have contributed to the overall contraction in credit after the referendum. Our focus in the figure and regression analysis is on the identification of cross-sectional differences in credit growth related to GBP losses.
} 
Figure 7: Firm-Level Credit Growth by Bank Type

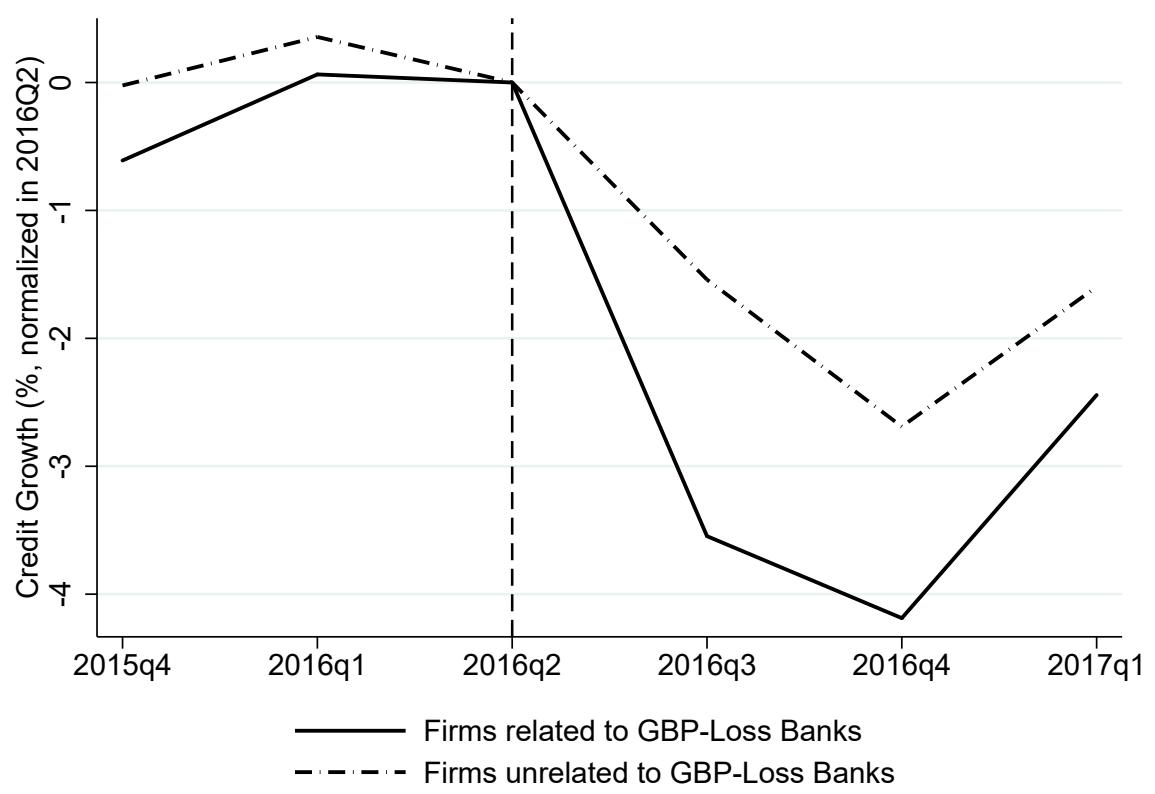

Notes: The figure shows the unconditional mean credit growth (in percent) at the firm level for firms with and without ex ante loans from GBP-loss banks. The vertical dashed line indicates 2016:Q2, when the Brexit referendum happened. Both series are normalized to take the value of 0 in 2016:Q2 and are based on a constant sample of firms that we observe in each quarter. Sources: Supervisory transaction-level derivatives available under European Markets Infrastructure Regulation (EMIR), banks' external positions (AUSTA), balance sheet statistic (BISTA), German credit register, and authors' calculations.

twice as much compared with the credit growth of firms without exposure to loss-realizing banks.

To measure the effects at the firm level more formally, we run the following baseline regression:

$$
\Delta \text { Credit }_{j}=\beta \cdot \text { GBP-Loss-Bank Reliance }_{j}+\alpha_{C}+\alpha_{I}+\epsilon_{j},
$$

where $\alpha_{C}$ and $\alpha_{I}$ are firm-country and firm-industry fixed effects, respectively. We compute robust standard errors clustered at the industry level.

Table 9 shows the results of the firm-level credit $r$ egressions. Column (1) shows that after the Brexit referendum, total firm credit declined about 1.9 percent, but the reduction was about 32 percent larger for firms with an ex ante exclusive reliance on banks with derivatives losses. Column (2) shows that this result holds after we control for industry fixed effects. Thus, it is not the case that firms with a large reliance on high-derivatives-loss banks are concentrated in certain 
Table 9: Credit-Growth Regressions at the Firm Level

\begin{tabular}{lccccc}
\hline & \multicolumn{5}{c}{ Dependent Variable: Bank Credit } \\
\cline { 2 - 6 } & All & All & German & No GBP Users & Nonfinancial \\
& $(1)$ & $(2)$ & $(3)$ & $(4)$ & $(5)$ \\
\cline { 2 - 6 } GBP-Loss-Bank Reliance & $-0.76^{* *}$ & $-0.63^{* *}$ & $-0.81^{* *}$ & $-0.66^{* *}$ & $-0.74 * * *$ \\
& $(0.32)$ & $(0.27)$ & $(0.36)$ & $(0.27)$ & $(0.20)$ \\
Constant & $-1.99^{* * *}$ & & & & \\
& $(0.50)$ & & & & \\
Industry FE & & & & Yes & Yes \\
Observations & No & Yes & Yes & 349,212 & 258,008 \\
\hline
\end{tabular}

Notes: This table shows the post-Brexit referendum bank credit growth at the firm level depending on a firm's credit dependence on a bank with GBP derivatives losses. The dependent variable Bank Credit is a firm's percentage change in credit outstanding between 2016:Q2 and 2016:Q3 as observed in the credit register. The independent variable Past Derivative-Loss-Bank Reliance is the 2016:Q2 exposure-weighted sum of creditors of the firm that incurred GBP net derivatives losses post-Brexit (see equation [6]). The sample in columns (3), (4), and (5) is restricted to German firms, firms without GBP forward usage, and nonfinancial firms, respectively. Robust standard errors clustered at the industry level are reported in parentheses. $* * * \mathrm{p}<0.01, * * \mathrm{p}<0.05, * \mathrm{p}<0.1$. Sources: Supervisory transaction-level derivatives available under European Markets Infrastructure Regulation (EMIR), banks' external positions (AUSTA), balance sheet statistic (BISTA), Bureau van Dijk's Orbis, and authors' calculations.

industries or countries that in general had a decline in credit. In columns (3) and (4), we show that the credit contraction also influenced firms that were not directly affected by the Brexit referendum: German firms and firms for which we do not observe any foreign exchange derivatives use in the full derivatives data set (which we use as a proxy for firms with no exposure to foreign exchange risk). We make this distinction to examine whether loss-realizing banks also reduced their lending to firms with no direct exposure to the pound to begin with. Importantly, for these firms, we also find a substantial reduction in credit, suggesting that the GBP-loss-realizing banks did not discriminate across their borrowers when adjusting their lending portfolio in response to this shock. Results presented in column (5) confirm that the larger credit-supply reduction by loss-realizing banks also affected nonfinancial firms and is thus likely to have had an immediate effect on real economic outcome variables.

In light of these strong and robust results, we next ask whether the cutback in credit leads to real effects at the firm level. To study the real effects, we focus on a subset of German nonfinancial 
Table 10: Real-Effects Regressions at the Firm Level

\begin{tabular}{lcccc}
\hline & \multicolumn{4}{c}{ Dependent Variable: } \\
\cline { 2 - 5 } & Bank Credit & Total Credit & Total Assets & $\begin{array}{c}\text { Investment } \\
(1)\end{array}$ \\
& $-1.97 * *$ & $-1.34 * *$ & $-0.87 * *$ & $-2.60^{* *}$ \\
\hline GBP-Loss-Bank Reliance & $(0.88)$ & $(0.54)$ & $(0.40)$ & $(1.09)$ \\
& & & & \\
Firm Controls & & & Yes & Yes \\
Industry Fixed Effects & Yes & Yes & Yes & Yes \\
Observations & 14,028 & 14,181 & 14,045 & 14,195 \\
\hline
\end{tabular}

Notes: This table shows real effects at the firm level depending on a firm's credit dependence on a bank with GBP derivatives losses. The dependent variable Bank Credit is the log difference in outstanding debt from the German credit register. Total Credit is the log difference in total outstanding debt from all sources, including debt recorded in the credit register and other sources such as non-German banks and bond markets. Total Assets is the log difference in total assets. Investment is the log difference in property, plant, and equipment (fixed tangible assets). All log differences refer to 2015 over 2016 changes using annual data, and coefficients are multiplied by 100. The independent variable GBP-Loss-Bank Reliance is the 2016:Q2 exposure-weighted sum of creditors of the firms that incurred GBP net derivatives losses post-Brexit (see equation [6]). Firm Controls include lagged values of employment, leverage (debt-to-assets ratio), and net current liabilities (as a percent of assets). The sample includes German nonfinancial firms with available information. Robust standard errors clustered at the industry level are reported in parentheses. $* * * \mathrm{p}<0.01, * * \mathrm{p}<0.05, * \mathrm{p}<0.1$. Sources: Supervisory transaction-level derivatives available under European Markets Infrastructure Regulation (EMIR), banks' external positions (AUSTA), balance sheet statistic (BISTA), Bureau van Dijk's Orbis, and authors' calculations.

firms for which we were able to obtain balance sheet and income statement data. In Table 10, we use different firm-level statistics to investigate these real effects for German firms. Our data are available at an annual frequency, and thus we estimate effects as a change between 2015 and 2016. First, in column (1), we replicate our main result from Table 9 for our subset of firms for which we have the relevant information. The result continues to hold and increases in absolute value. Given that the results in Table 9 are based on exposures reported in the German credit register data set, in column (2), we also verify that overall debt growth, which takes into account other sources of debt financing, declines more when the main lenders are facing GBP losses. Although the point estimate on the more comprehensive debt measure is somewhat smaller (in absolute value), the significant negative coefficient shows that affected firms were not able to substitute their lost borrowing with increased funding from other banks — such as foreign banks, which are not captured in the credit 
register-or with the issuance of debt to the marketplace, which is rather uncommon, given the bank-dominated German economy.

In column (3), we show that total-asset growth is significantly smaller for firms with reliance on derivative-loss-realizing banks. Thus, firms with reliance on loss-bearing banks shrink the overall size of their business operations. Finally, in column (4), we show that investment, as measured by the growth rate in plant, property, and equipment, declines particularly strongly for banks with a relationship to loss-realizing banks. Figure A8 shows the total decline in investment after the Brexit referendum using aggregate data on all private investments in Germany. Our firm-level results suggest that the drop in aggregate private investment is, at least in part, driven by the channel outlined in this paper. In unreported results, we also find a statistically weak decline in cash holdings, but we do not find evidence on employment effects, potentially due to strong employment protection laws in Germany, which render adjustments in the workforce very difficult and costly.

Further, we examine additional heterogeneity in the transmission to the real economy. In particular, we assess the extent to which the effects are more pronounced for firms that face a higher cost of switching to other sources of funding after their relationship (bank) lender faces losses from GBP exposure. ${ }^{33}$ Following the financial frictions literature that places special emphasis on smaller firms (e.g., Gertler and Gilchrist 1994), which may be more vulnerable to credit shocks due to lower transparency, we estimate differential effects on credit and investment depending on firm size.

Table 11 shows results that are similar to those of previous regressions, but now they are for large firms and smaller firms. Small firms are defined as having fewer employees than those in the bottom tercile of the cross-sectional distribution in 2015; all other firms are grouped into the category of large firms. Our results show that credit and investment effects are concentrated in smaller firms, for which we estimate substantially larger coefficients. In particular, the effect on total credit is more than three times larger (in absolute value) for small firms compared with large firms. For investment, the effect on small firms is five times larger (in absolute value) than it is

\footnotetext{
${ }^{33}$ Those alternative sources may include other unaffected banks, either German or foreign, or bond markets, although Germany has a bank-based financial system with only a few very large firms accessing market-based sources of debt financing.
} 
Table 11: Real-Effects Regressions for Small vs. Large Firms

\begin{tabular}{lccccc}
\hline & \multicolumn{4}{c}{ Dependent Variable: } \\
\cline { 2 - 3 } & \multicolumn{2}{c}{ Total Credit } & & \multicolumn{2}{c}{ Investment } \\
\cline { 2 - 3 } \cline { 5 - 6 } & Large Firms & Small Firms & & Large Firms & Small Firms \\
& $(1)$ & $(2)$ & & $(3)$ & $(4)$ \\
\hline GBP-Loss-Bank Reliance & $-0.77^{*}$ & $-2.71 * *$ & & -1.13 & $-5.62^{* * *}$ \\
& $(0.42)$ & $(1.19)$ & & $(0.94)$ & $(1.54)$ \\
Firm Controls & & & & Yes \\
Industry Fixed Effects & Yes & Yes & & Yes & Yes \\
Observations & 9,853 & 4,328 & & 9,864 & 4,331 \\
\hline
\end{tabular}

Notes: This table shows heterogeneous real effects at the firm level depending on the size of the firm. Total Credit is the log difference in total outstanding debt from all sources, including debt recorded in the credit register, borrowing from non-German banks, and borrowing from bond markets. Investment is the log difference in property, plant, and equipment (fixed tangible assets). All log differences refer to 2015 over 2016 changes using annual data, and coefficients are multiplied by 100. The independent variable GBP-Loss-Bank Reliance is the 2016:Q2 exposure-weighted sum of a firm's creditors that incurred GBP net derivatives losses post-Brexit (see equation [6]). Firm Controls include lagged values of cash holdings, employment, total assets, fixed assets, and fixed tangible assets. Small Firms are defined as firms with fewer employees than the lower tercile of the cross-firm distribution in 2015; Large Firms are firms in the two upper terciles. The sample includes German nonfinancial firms with available income statements and balance sheet information. Robust standard errors clustered at the industry level are reported in parentheses. $* * *$ $\mathrm{p}<0.01, * * \mathrm{p}<0.05, * \mathrm{p}<0.1$. Sources: Supervisory transaction-level derivatives available under European Markets Infrastructure Regulation (EMIR), banks' external positions (AUSTA), balance sheet statistic (BISTA), Bureau van Dijk's Orbis, and authors' calculations.

on large firms, for which we still find a negative, although not significant, effect. The differential investment effect for small versus large firms is also highly statistically significant. These effects are identified within industry; that is, we compare the investment and credit growth of two small firms in the same industry with different exposures to GBP-loss-bearing banks.

The finding that banking relationships matter more for smaller borrowers is in line with friction in credit markets being rooted in asymmetric information problems and is consistent with previous empirical evidence (e.g., Chodorow-Reich 2013). Finally, our finding that real effects are concentrated on small firms is not only relevant for isolating the economic transmission channel, it also has important macroeconomic implications, given that small and medium-sized enterprises are often characterized as the backbone of the German economy, accounting for about 55 percent of the country's economic output and employing about 60 percent of all workers in 2015 (Institut für 
Mittelstandsforschung). 


\section{Conclusion}

The market for foreign exchange risk protection is one of the largest financial markets available today. Firms that are active in international product and factor markets use the forward market to hedge their risk exposure, thereby transferring the foreign exchange risk to banks that are central dealers in this market. We identify this risk migration from firms to the banking sector and the real effects on the German economy in the context of the Brexit referendum in 2016. In particular, our findings show that foreign exchange risk that migrates to the banking sector and is not fully intermediated can be transformed into real effects to the broader economy through adjustments in bank credit supply and related contraction in firms' investment.

Our results have important implications for macroeconomic and financial models that focus on the transmission of exchange rate shocks to the economy. In particular, we show that balance sheet effects of exchange rate shocks are transmitted not only through firms that have exchange rate exposure through international product or factor markets, but also through the banking sector, if firms hedge the risk exposure by using financial derivatives and the banking sector does not fully intermediate the risk to other agents in the economy. Such a migration then has the potential to sizably amplify shocks of systemic scope, which, if ignored in international macroeconomic models, could lead to incomplete views of the effects of exchange rate movements.

Our results also have important macroprudential implications. First, and most directly, when designing regulatory foreign exchange risk charges for banks, policymakers should take into account the financial stability effects documented in this paper, in particular, spillovers to banks' credit books. Second, and more broadly, while we do not address normative questions in this paper, our findings suggest that discussions about the optimal reallocation of foreign exchange risk in the economy (who should be holding the risks) should consider the transmission channels through the banking system. 


\section{References}

Abbassi, P. and Bräuning, F. (2020). Demand Effects in the FX Forward Market: Micro Evidence from Banks' Dollar Hedging. Review of Financial Studies, forthcoming.

Abbassi, P., Iyer, R., Peydro, J.-L., and Rodríguez Tous, F. (2016). Securities Trading by Banks and Credit Supply: Micro-Evidence from the Crisis. Journal of Financial Economics, 121(3):569594.

Aghion, P., Bacchetta, P., and Banerjee, A. (2004). A Corporate Balance-Sheet Approach to Currency Crises. Journal of Economic Theory, 119(1):6-30.

Amiti, M., Itskhoki, O., and Konings, J. (2014). Importers, Exporters, and Exchange Rate Disconnect. American Economic Review, 104(7):1942-1978.

Amiti, M. and Weinstein, D. E. (2011). Exports and Financial Shocks. Quarterly Journal of Economics, 126(4):1841-1877.

Antras, P., Fort, T. C., and Tintelnot, F. (2017). The Margins of Global Sourcing: Theory and Evidence from US Firms. American Economic Review, 107(9):2514-2564.

Begenau, J., Piazzesi, M., and Schneider, M. (2015). Banks' Risk Exposures. Working Paper 21334, National Bureau of Economic Research.

Berger, A. N. and Bouwman, C. H. S. (2009). Bank Liquidity Creation. Review of Financial Studies, 22(9):3779-3837.

Berman, N., Martin, P., and Mayer, T. (2012). How Do Different Exporters React to Exchange Rate Changes? Quarterly Journal of Economics, 127(1):437-492.

Bernanke, B. and Gertler, M. (1989). Agency Costs, Net Worth, and Business Fluctuations. American Economic Review, 79(1):14-31.

Bordo, M. D., Taylor, A. M., and Williamson, J. G. (2003). Globalization in Historical Perspective. National Bureau of Economic Research.

Borusyak, K., Hull, P., and Jaravel, X. (2018). Quasi-Experimental Shift-Share Research Designs. Working Paper 24997, National Bureau of Economic Research.

Broda, C. and Weinstein, D. E. (2006). Globalization and the Gains from Variety. Quarterly Journal of Economics, 121(2):541-585.

Brunnermeier, M. K., Gorton, G., and Krishnamurthy, A. (2011). Risk Topography. NBER Macroeconomics Annual 2011, 26:149-176.

Brunnermeier, M. K. and Sannikov, Y. (2014). A Macroeconomic Model with a Financial Sector. American Economic Review, 104(2):379-421.

Bruno, V. and Shin, H. S. (2014). Cross-Border Banking and Global Liquidity. Review of Economic Studies, 82(2):535-564. 
Bruno, V. and Shin, H. S. (2015). Capital Flows and the Risk-Taking Channel of Monetary Policy. Journal of Monetary Economics, 71:119 - 132.

Bräuning, F. and Ivashina, V. (2016). Monetary Policy and Global Banking. Working Paper 23313, National Bureau of Economic Research.

Caballero, R. and Krishnamurthy, A. (2003). Excessive Dollar Debt: Financial Development and Underinsurance. Journal of Finance, 58(2):867-893.

Chodorow-Reich, G. (2013). The Employment Effects of Credit Market Disruptions: Firm-Level Evidence from the 2008-9 Financial Crisis. Quarterly Journal of Economics, 129(1):1-59.

Desai, M. A., Foley, C. F., and Forbes, K. J. (2008). Financial Constraints and Growth: Multinational and Local Firm Responses to Currency Depreciations. Review of Financial Studies, 21(6):28572888.

Du, W., Tepper, A., and Verdelhan, A. (2018). Deviations from Covered Interest Rate Parity. Journal of Finance, 73(3):915-957.

Duffie, D. (2010). The Failure Mechanics of Dealer Banks. Journal of Economic Perspectives, 24(1):51-72.

Ethier, W. (1973). International Trade and the Forward Exchange Market. American Economic Review, 36(3):494-503.

Froot, K. A., Scharfstein, D. S., and Stein, J. C. (1993). Risk Management: Coordinating Corporate Investment and Financing Policies. Journal of Finance, 48(5):1629-1658.

Froot, K. A. and Stein, J. C. (1998). Risk Management, Capital Budgeting, and Capital Structure Policy for Financial Institutions: An Integrated Approach. Journal of Financial Economics, 47(1):55-82.

Gabaix, X. and Maggiori, M. (2015). International Liquidity and Exchange Rate Dynamics. Quarterly Journal of Economics, 130(3):1369-1420.

Gertler, M. and Gilchrist, S. (1994). Monetary Policy, Business Cycles, and the Behavior of Small Manufacturing Firms. Quarterly Journal of Economics, 109(2):309-340.

Gertler, M. and Kiyotaki, N. (2010). Financial Intermediation and Credit Policy in Business Cycle Analysis. In Handbook of Monetary Economics, volume 3, pages 547-599. Elsevier.

Goldsmith-Pinkham, P., Sorkin, I., and Swift, H. (2018). Bartik Instruments: What, When, Why, and How. Working Paper 24408, National Bureau of Economic Research.

Gomolka, M., Munzert, C., and Stahl, H. (2020a). External Position of Banks 03/2002 - 12/2019. Data report 2020-02, Deutsche Bundesbank Research Data and Service Centre.

Gomolka, M., Schäfer, M., and Stahl, H. (2020b). Monthly Balance Sheet Statistics (BISTA). Data Report 2020-04, Deutsche Bundesbank Research Data and Service Centre. 
Gopinath, G., Boz, E., Casas, C., Díez, F. J., Gourinchas, P.-O., and Plagborg-Møller, M. (2020). Dominant Currency Paradigm. American Economic Review, 110(3):677-719.

Greenstone, M., Mas, A., and Nguyen, H.-L. (2020). Do Credit Market Shocks Affect the Real Economy? Quasi-experimental Evidence from the Great Recession and 'Normal' Economic Times. American Economic Journal: Economic Policy, 12(1):200-225.

Hale, G. and Arteta, C. (2009). Currency Crises and Foreign Credit in Emerging Markets: Credit Crunch or Demand Effect? European Economic Review, 53(7):758 - 774.

Holmstrom, B. and Tirole, J. (1997). Financial Intermediation, Loanable Funds, and the Real Sector. Quarterly Journal of Economics, 112(3):663-691.

Ivashina, V., Scharfstein, D. S., and Stein, J. C. (2015). Dollar Funding and the Lending Behavior of Global Banks. Quarterly Journal of Economics, 130(3):1241-1281.

Khwaja, A. I. and Mian, A. (2008). Tracing the Impact of Bank Liquidity Shocks: Evidence from an Emerging Market. American Economic Review, 98(4):1413-1442.

Krugman, P. (1995). Growing World Trade: Causes and Consequences. Brookings Papers on Economic Activity, 26(1, 25th Anniversary Issue):327-377.

Morais, B., Peydró, J.-L., Roldán-Pena, J., and Ruiz-Ortega, C. (2019). The International Bank Lending Channel of Monetary Policy Rates and QE: Credit Supply, Reach-for-Yield, and Real Effects. Journal of Finance, 74(1):55-90.

Paravisini, D., Rappoport, V., Schnabl, P., and Wolfenzon, D. (2015). Dissecting the Effect of Credit Supply on Trade: Evidence from Matched Credit-Export Data. Review of Economic Studies, 82(1):333-359.

Peek, J. and Rosengren, E. S. (1997). The International Transmission of Financial Shocks: The Case of Japan. American Economic Review, 87(4):495-505.

Peek, J. and Rosengren, E. S. (2000). Collateral Damage: Effects of the Japanese Bank Crisis on Real Activity in the United States. American Economic Review, 90(1):30-45.

Petersen, M. A. and Rajan, R. G. (1995). The Effect of Credit Market Competition on Lending Relationships. Quarterly Journal of Economics, 110(2):407-443.

Rampini, A. A. and Viswanathan, S. (2018). Financial Intermediary Capital. Review of Economic Studies, 86(1):413-455.

Rampini, A. A., Viswanathan, S., and Vuillemey, G. (2020). Risk Management in Financial Institutions. Journal of Finance, 75(2):591-637.

Schild, C.-J., Schultz, S., and Wieser, F. (2017). Linking Deutsche Bundesbank Company Data using Machine-Learning-Based Classification. Technical Report 2017-01, Deutsche Bundesbank Research Data and Service Centre. 
Schnabl, P. (2012). The International Transmission of Bank Liquidity Shocks: Evidence from an Emerging Market. Journal of Finance, 67(3):897-932.

Thompson, J. R. (2010). Counterparty Risk in Financial Contracts: Should the Insured Worry About the Insurer? Quarterly Journal of Economics, 125(3):1195-1252.

Yi, K. (2003). Can Vertical Specialization Explain the Growth of World Trade? Journal of Political Economy, 111(1):52-102.

Öztekin, and Flannery, M. J. (2012). Institutional Determinants of Capital Structure Adjustment Speeds. Journal of Financial Economics, 103(1):88-112. 


\section{A Theoretical Framework}

We study the effects of foreign exchange risk migration in a two-period model. In period 0 , a representative firm can hedge part of its foreign exchange exposure by trading forward contracts with a representative bank. In period 1, derivatives contracts clear, the loan market opens, and investment takes place.

The fundamental source of uncertainty in the model is the value of the period- 1 foreign exchange rate. To focus on the role of uncertainty in a setup that is as simple as possible, we assume the spot exchange rate in period 1 has a two-point distribution with equal probability:

$$
S= \begin{cases}1+\delta & \text { with prob. } p=0.5 \\ 1-\delta & \text { with prob. } 1-p=0.5\end{cases}
$$

where $0<\delta<1$. Thus, with 0.5 probability the foreign currency depreciates or appreciates by $100 \delta$ percent. The mean future spot rate is normalized to $\mathbb{E} S=1$, and our sole focus is on the standard deviation $\delta$ that characterizes the exchange rate uncertainty.

Throughout the model exposition, all exchange rates are expressed in units of domestic currency per unit of foreign currency; that is, $S=1.5$ means that a unit of foreign currency buys 1.5 units of domestic currency.

\section{A.1 Firm}

We consider a simple model in the spirit of Froot et al. (1993). The key feature that generates hedging demand in response to an increase in uncertainty is the concavity of the firm's profit function. The firm has an initial endowment with a value that is subject to foreign exchange risk. In particular, the endowment $w_{0}>0$ is denominated in foreign currency and must be converted into domestic currency before it can be invested in the domestic production process. This endowment is,

for example, a result of foreign revenues from existing production and sales. For simplicity, we abstract from wealth already held in domestic currency. 
Production takes place in period 1 and is funded entirely through investment made in local currency. Thus, so that it can invest, the firm wants to convert the initial endowment held in foreign currency into domestic currency. Foreign exchange risk introduces uncertainty about the investment value funded with equity. In period 0 , the firm therefore decides to hedge a share $h \in(0,1)$ of the initial wealth by buying domestic currency of value $X^{f} h w_{0}$ in the forward market, where $X^{f}$ is the forward exchange rate (expressed in domestic currency per foreign currency), which the firm takes as given. The remaining, unhedged share $(1-h)$ of wealth is converted at the period-1 spot rate $S$. Thus, in period 1 , the firm has a total equity value of

$$
w=\left(h X^{f}+(1-h) S\right) w_{0},
$$

which is available for investment in production. From a period-0 perspective, if not all exposure is hedged, $h=1$, then $w$ is random. We focus on the case in which the forward exchange rate trades at a discount $\left(X^{f}<1\right)$, that is, in expectation, hedging, reducing the period-1 wealth. Moreover, hedging is associated with a convex position cost, which we assume to be a quadratic form $\left(h w_{0}\right)^{2}$. This cost is a shortcut for modeling fees or margin requirements imposed by the dealer bank.

In addition to the amount of hedging, the firm decides on the value of debt $L$ to hold, creating a total amount invested of $I=w+L$. Borrowing funds in the loan market is associated with an interest rate $r$, which the firm takes as given. The firm decides on the amount of leverage in period 1 after the foreign exchange risk materializes; thus, external funding enables the firm to smooth out investment in light of exchange-rate and related equity-funding uncertainty. Finally, the firm uses a concave (decreasing returns-to-scale) production technology, which we assume for analytical tractability to be of a logarithmic form, $y=\theta \log (I)$, where $y$ is total production output sold at a unit price normalized to 1 , and $\theta>0$ is a scale parameter.

We solve the model backward by first determining the optimal amount of leverage in period 1 for a given value of $w$, and then deriving the optimal hedging decision in period 0 given the optimal leverage value. 
The firm's optimal leverage decision in period 1 is given by

$$
\max _{\{L\}} \theta \log (w+L)-(1+r) L
$$

and the optimal amount of leverage is given by

$$
L^{d}=\frac{\theta}{1+r}-w
$$

where $\theta>(1+r) w$ is assumed to hold for all $w>0$. Thus, the optimal leverage is a function of the firm's equity funds, which are random if $h<1$. In particular, if $w$ decreases due to unhedged currency exposure and a depreciation of the foreign currency, the firm wants to borrow more to maintain investment at the optimal level. Moreover, from equation (11) we find

$$
\frac{\partial L^{d}}{\partial r}<0
$$

that is, the firm wants to reduce borrowing as the interest rate increases and obtaining external financing becomes more costly.

Moving to period 0 , the loan interest rate $r$ is a random variable that depends on the exchange rate movements in period 1 , with values given by

$$
r= \begin{cases}r^{H} & \text { if } S=1+\delta \\ r^{L} & \text { if } S=1-\delta\end{cases}
$$

where the superscript $H(L)$ indicates the interest rate in the regime where $S$ is high (low). In period 0 , the firm thus maximizes expected profits by choosing the hedging ratio subject to the optimal 
leverage decision:

$$
\begin{gathered}
\max _{\{h\}} \mathbb{E}\left(\theta \log \left(w+L^{d}\right)-(1+r) L^{d}-\left(h w_{0}\right)^{2}\right) \\
\text { s.t. } L^{d}=\frac{\theta}{1+r}-w(h) \\
w=\left(h X^{f}+(1-h) S\right) w_{0},
\end{gathered}
$$

where the expectation is taken with respect to the period-1 exchange rate. The solution to the problem leads to the firm's demand function for forward contracts:

$$
F^{d}=\frac{1}{4}\left(-r^{H}\left(\delta-X^{f}+1\right)+r^{L}\left(\delta+X^{f}-1\right)+2 X^{f}-2,\right.
$$

which is upward sloping in $X^{f}$ (that is, downward sloping in the price of domestic currency $1 / X^{f}$ ):

$$
\frac{\partial F^{d}}{\partial X^{f}}=\frac{1}{2}+\frac{1}{4}\left(r^{H}+r^{L}\right)>0 .
$$

Thus, the firm wants to sell more foreign currency forward contracts if the forward exchange rate is more favorable for the firm; that is, if the firm obtains more domestic currency per unit of foreign currency. Similarly, we can show that $\frac{\partial F^{d}}{\partial r^{H}}=\frac{\partial F^{d}}{\partial r^{L}}=-\frac{1}{4}\left(1-\delta-X^{f}\right)>0$ if $1-X^{f}<\delta$; that is, provided the exchange rate uncertainty $\delta$ is high enough relative to the forward discount, the firm wants to hedge more as the interest rate increases to reduce fluctuations in domestic-currency wealth and the associated need to access the loan market for costly external funding.

Moreover, we can further derive the partial derivative with respect to the exchange rate uncertainty parameter $\delta$,

$$
\frac{\partial F^{d}}{\partial \delta}=\frac{1}{4}\left(r^{L}-r^{H}\right)>0,
$$

if $r^{L}>r^{H}$. Thus, the firm's demand for forward contracts shifts up as the exchange rate uncertainty increases if the interest rate is higher in the regime where the domestic currency appreciates. The reason is that, due to the concavity of the firm's production function, large downward fluctuations 
in the exchange rate imply a disproportionate output and associated profit loss. The firm wants to avoid this risk and hedge more as the uncertainty increases.

It is important to highlight that, for simplicity, we focus only on foreign exchange risk in equity-funded investment. More generally, we also could build foreign exchange risk into the firm's profits through other channels, for example, through foreign revenues (for example, exporters), input cost more generally (for example, importers), or the cost of foreign-currency debt. Also, note that we focus on hedging demand in one direction (forward sale of foreign currency), which may be viewed as a (for example, sectoral) net demand for short contracts.

\section{A.2 Bank}

The firm's counterparty in the loan and derivatives market is a representative bank that provides credit and foreign exchange derivatives services. In period 1, the loan market opens, and the bank chooses to issue loans of value $L$ funded through deposits $D$ and fixed equity capital $K$. Loans yield a gross return of $1+r$, which the bank takes as given, while collecting deposits is associated with a convex cost $c(D)$. These costs can be interpreted as adjustment costs to the depository base or balance sheet costs.

The bank also provides foreign exchange forward contracts of total notional value $F$ at a forward rate $X^{f}$. More precisely, $F$ is the amount of foreign currency that in period 0 , the bank agrees to buy in period 1. Providing these derivatives services may be associated with a convex cost $c(F)$. To meet its obligations in the forward market at period 1, the bank delivers domestic currency out of initial wealth and converts the foreign currency received at the future spot rate $S$. We can think of the value $F$ as the bank's net position in foreign exchange derivatives trading. For example, while we do not model this explicitly, the bank could engage in an interdealer market to hedge part of the foreign exchange risk resulting from firm (client) trades. Any nonzero net derivatives position exposes the bank to exchange rate risk, which materializes in period 1 and leads to either capital 
losses or gains. ${ }^{34}$

The bank's lending is subject to a capital constraint, which requires a share $\alpha$ of the loan portfolio to be funded with equity capital. A capital constraint is a standard assumption in the banking literature (e.g., Ivashina et al. 2015) and is most naturally interpreted as a regulatory capital constraint, but it could also be due to internal risk management requirements. (In principle, we could add the requirement that net currency exposure needs to be funded partly with equity, but we abstract from this channel for simplicity.) We assume that in equilibrium, the capital constraint is binding, which means that the bank foregoes some positive net-present-value projects. In addition, a fixed equity capital means that raising equity is prohibitively (infinitely) costly in the short run. Given the binding capital constraint in period 1, when capital gains or losses from foreign exchange derivatives trading have been realized, the loan supply is given by

$$
L^{s}=\frac{K-\left(X^{f}-S\right) F}{\alpha}
$$

where $K>\left(X^{f}-S\right) F$ is assumed to hold. Thus, due to the binding capital constraint, the loan supply in period 1 is inelastic, as it does not directly depend on $r$.

In period 0 , the bank chooses the value of forward contracts it purchases to maximize expected profits while taking the prices in the loan and derivatives market as given:

$$
\begin{array}{cl}
\max _{\{L\}} & \mathbb{E}\left((1+r) L^{s}-c(D)-\left(X^{f}-S\right) F\right) \\
\text { s.t. } & L^{s}=D+K \\
& K=\alpha L^{s}-\left(X^{f}-S\right) F .
\end{array}
$$

To obtain an analytically tractable solution for the optimal forward provision, we assume a quadratic cost functions for lending and forwards of the form $c_{1}(L)^{2}$ and $c_{2}(F)^{2}$, respectively, with scaling

\footnotetext{
${ }^{34}$ We do not consider potential regulatory charges for nonzero net derivatives positions. For simplicity, we also assume the bank has no on-balance-sheet exposure to the foreign currency. In our empirical analysis, we comprehensively control for any such on-balance-sheet exposure.
} 
parameters $c_{1}, c_{2}>0$. Substituting out $D$ and $L$, we can then derive the bank's derivatives supply function:

$$
F^{s}=\frac{\alpha\left(2 \alpha+(1+\delta) r^{H}+(1-\delta) r^{L}+2\right)-4 c_{1} K}{4\left(\alpha^{2} c_{2}+c_{1}\left(\delta^{2}+\left(X^{f}-1\right)^{2}\right)\right)}-\frac{\alpha\left(2 \alpha+r^{H}+r^{L}+2\right)+4 c_{1} K}{4\left(\alpha^{2} c_{2}+c_{1}\left(\delta^{2}+\left(X^{f}-1\right)^{2}\right)\right)} X^{f}
$$

While the expression is lengthy, it is easy to show that the bank's derivatives supply is decreasing in $X^{f}$ :

$$
\frac{\partial F^{s}}{\partial X^{f}}=-\frac{\alpha\left(2 \alpha+r^{H}+r^{L}+2\right)+4 c_{1} K}{4\left(\alpha^{2} c_{2}+c_{1}\left(\delta^{2}+\left(X^{f}-1\right)^{2}\right)\right)}<0
$$

In other words, when the forward rate increases, that is, becomes more unfavorable for the bank, the bank wants to reduce its derivatives exposure.

\section{A.3 Equilibrium}

We can derive the equilibrium prices in the derivatives and loan markets by equating demand and supply in the forward and loan markets. Equilibrium in the loan market is state dependent on the exchange rate realization in period 1. Overall, equilibrium is characterized by a vector $\left(X^{f}, r(S)\right)$ such that $F^{s}=F^{d}$ and $L^{S}(S)=L^{d}(S)$ for all $S$. Figure A1 illustrates the qualitative impact of an increase in the exchange rate uncertainty $\delta$ on credit- and derivatives-market outcomes. The figure illustrates the qualitative features of the equilibrium for the following parameterization: $\theta=1.12, \alpha=0.1, K=1, w_{0}=0.05, c_{1}=0.48, c_{2}=0$.

Panel (a) shows that the total hedging activity increases as uncertainty rises. The increased derivatives use leads to price pressure that increases the forward discount, as panel (b) shows. This forward discount makes the bank willing to risk foreign exchange exposure in order to receive an expected higher return from derivatives trades while potentially bearing a loss in its credit business in a state of the world where the foreign currency depreciates. Panels (c) through (f) of Figure A1 show the credit market outcomes for the high and low realization of the spot rate. With a high $S$, that is, an appreciation of the foreign currency, the interest rate falls and loan volume increases. This is a result of the bank's capital gains from its derivatives market leading to an increased loan 


\section{Figure A1: Exchange Rate Uncertainty and Derivatives and Credit Market Equilibrium}

(a) FX Forward Volume

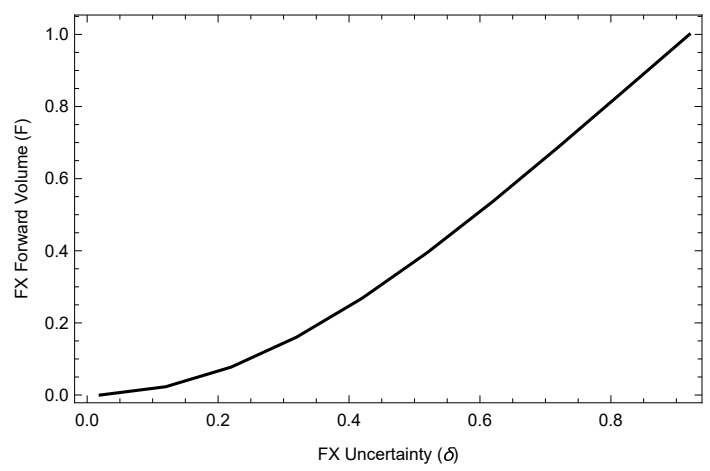

(c) Loan Volume, Low $S$

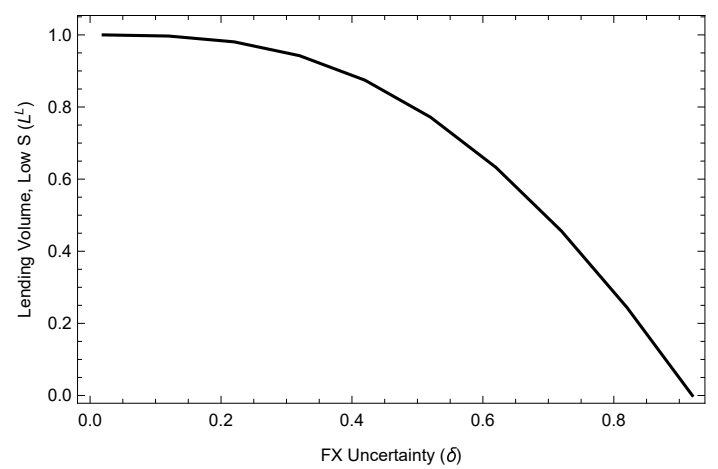

(e) Loan Volume, High $S$

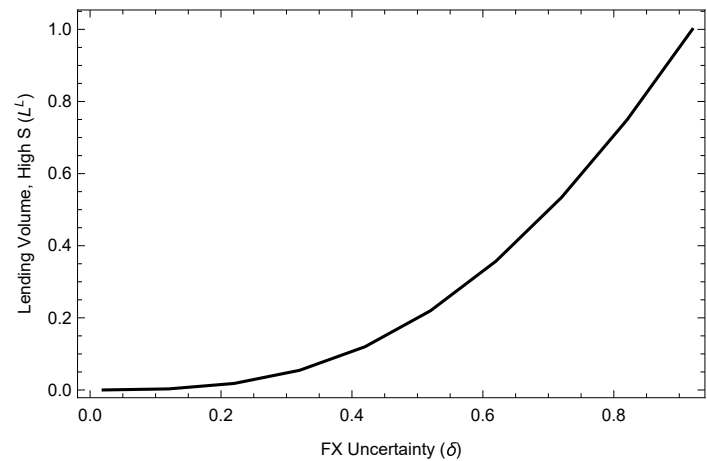

(b) FX Forward Rate

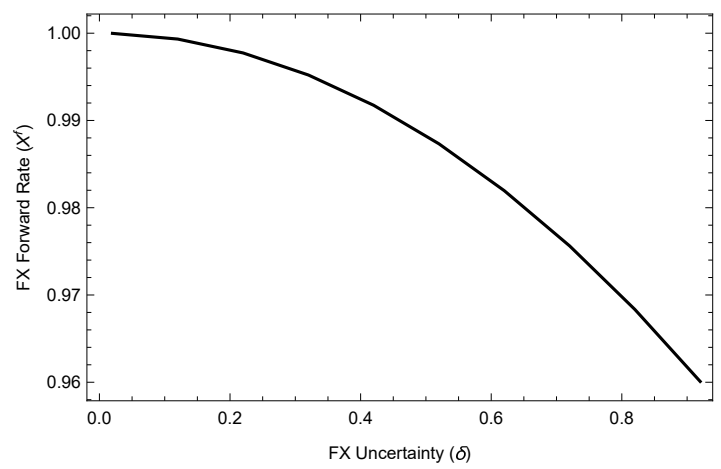

(d) Loan Rate, Low $S$

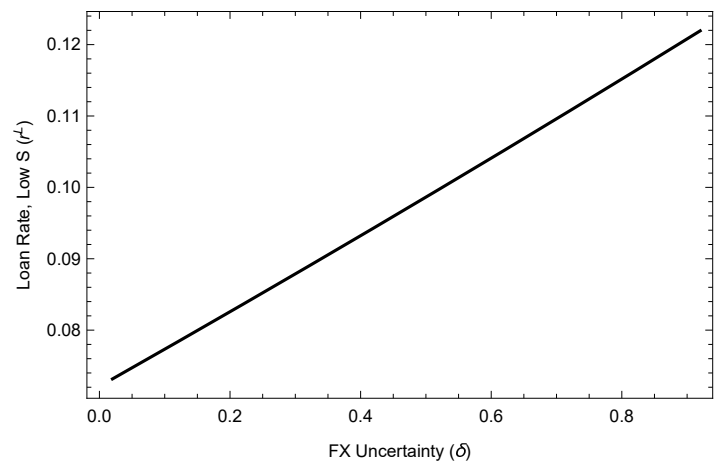

(f) Loan Rate, High $S$

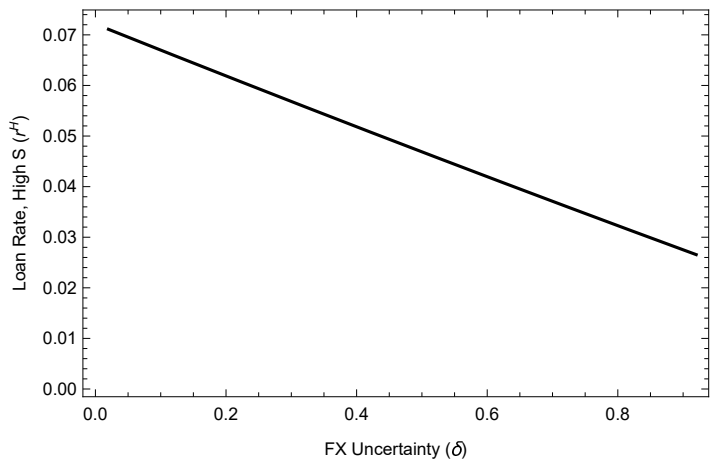

Notes: The figure shows the qualitative impact of changes in foreign exchange uncertainty $(\delta \in(0,1))$ on derivatives and credit market outcomes. Panels (a) and (b) show the forward market equilibrium, panels (c) and (d) show the credit market equilibrium if the foreign currency depreciates (low $S$ ), and panels (e) and (f) show the credit market equilibrium if the foreign currency appreciates (high $S$ ). The figure shows normalized equilibrium quantities that take values between 0 and 1 .

supply. On the other hand, if $S$ falls, the bank incurs losses on its derivatives exposure to the foreign currency, and credit contracts and loan rates increase. 


\section{B Additional Figures and Tables}

Figure A2: Key Foreign Exchange Rates around Brexit Referendum

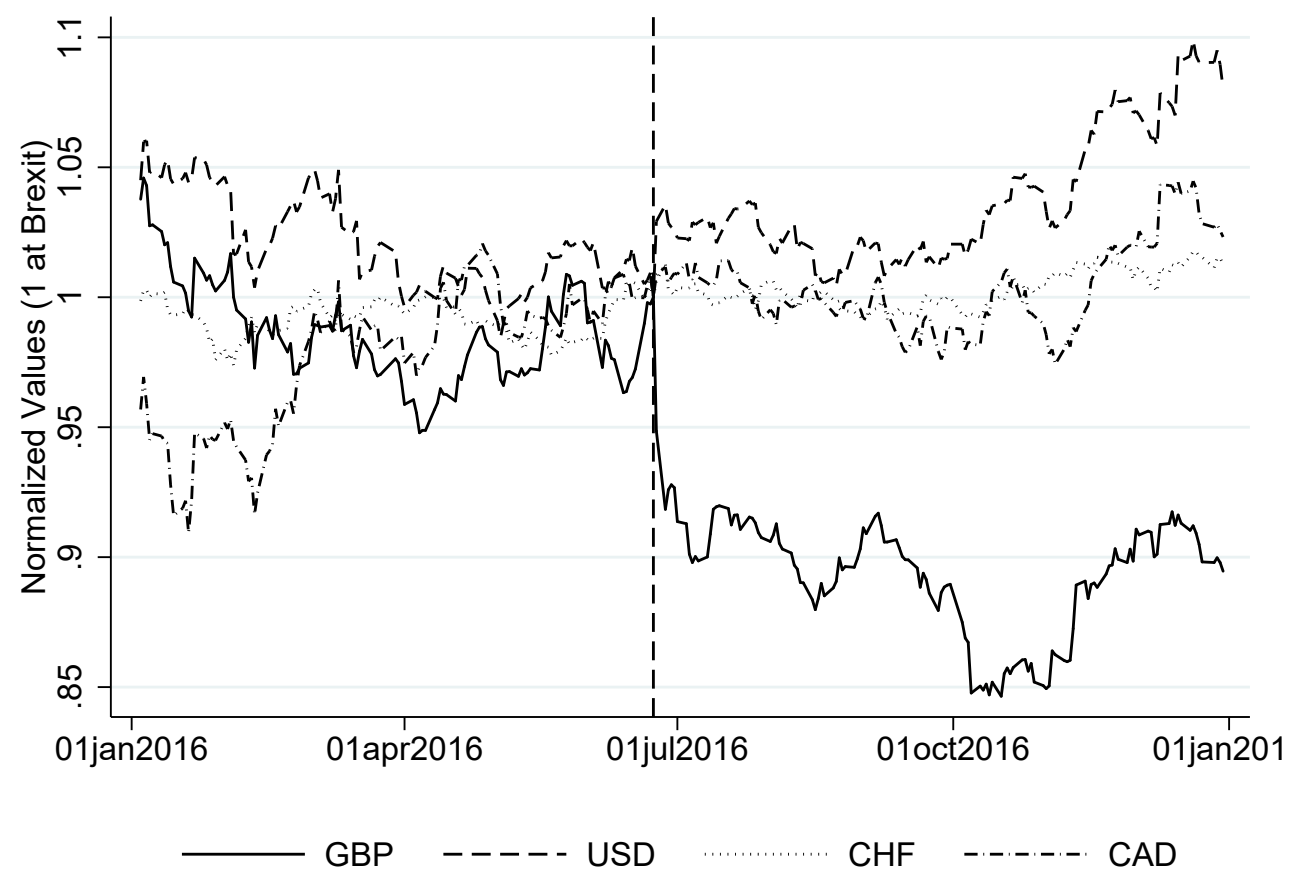

Notes: Value of foreign currencies against the euro around Brexit referendum. Sources: Bloomberg and authors' calculations. 
Figure A3: Bid-Ask Spread in Pound-Euro Forward Market

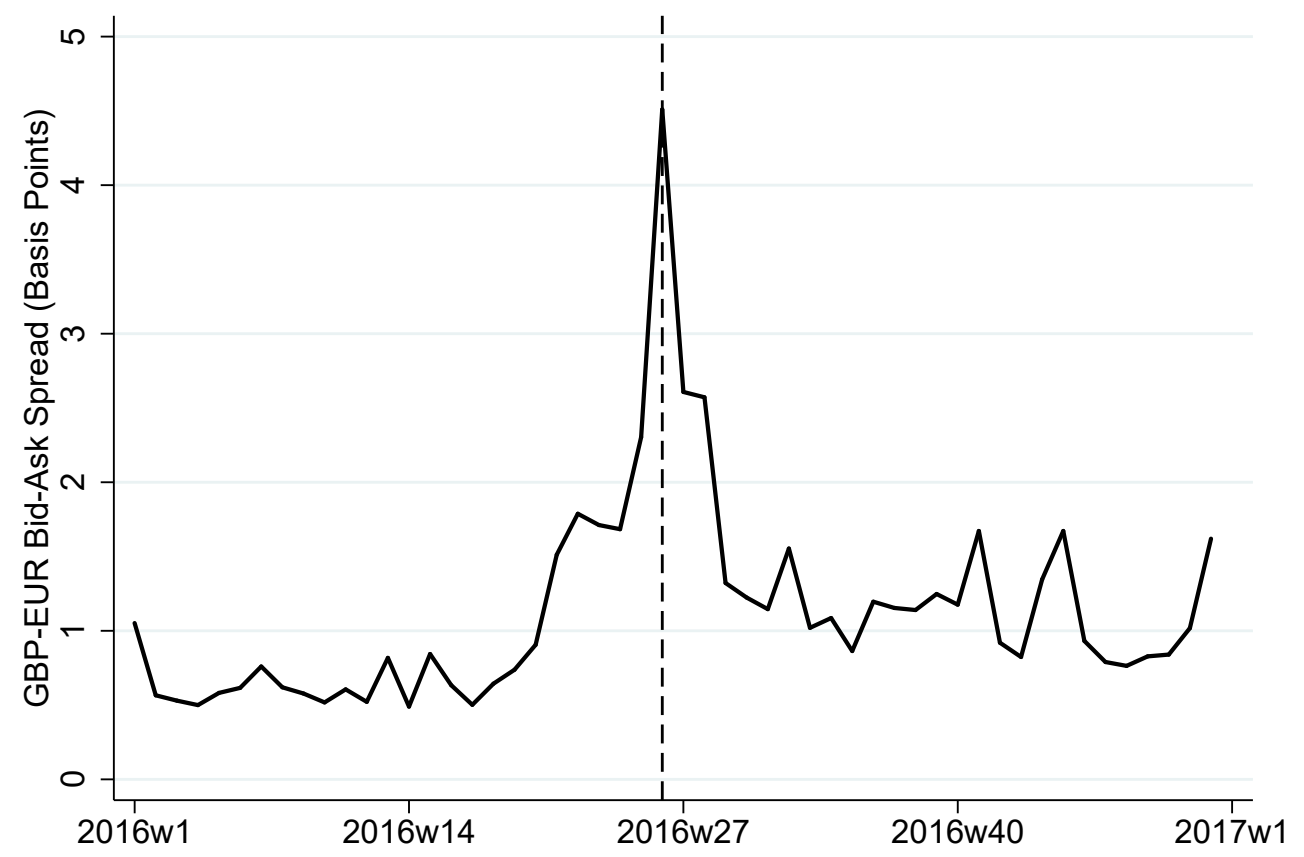

Notes: Bid-ask spread on three-month EUR/GBP forward contracts. Sources: Bloomberg and authors' calculations. 


\section{Figure A4: German Banking System Net Long GBP Contracts}

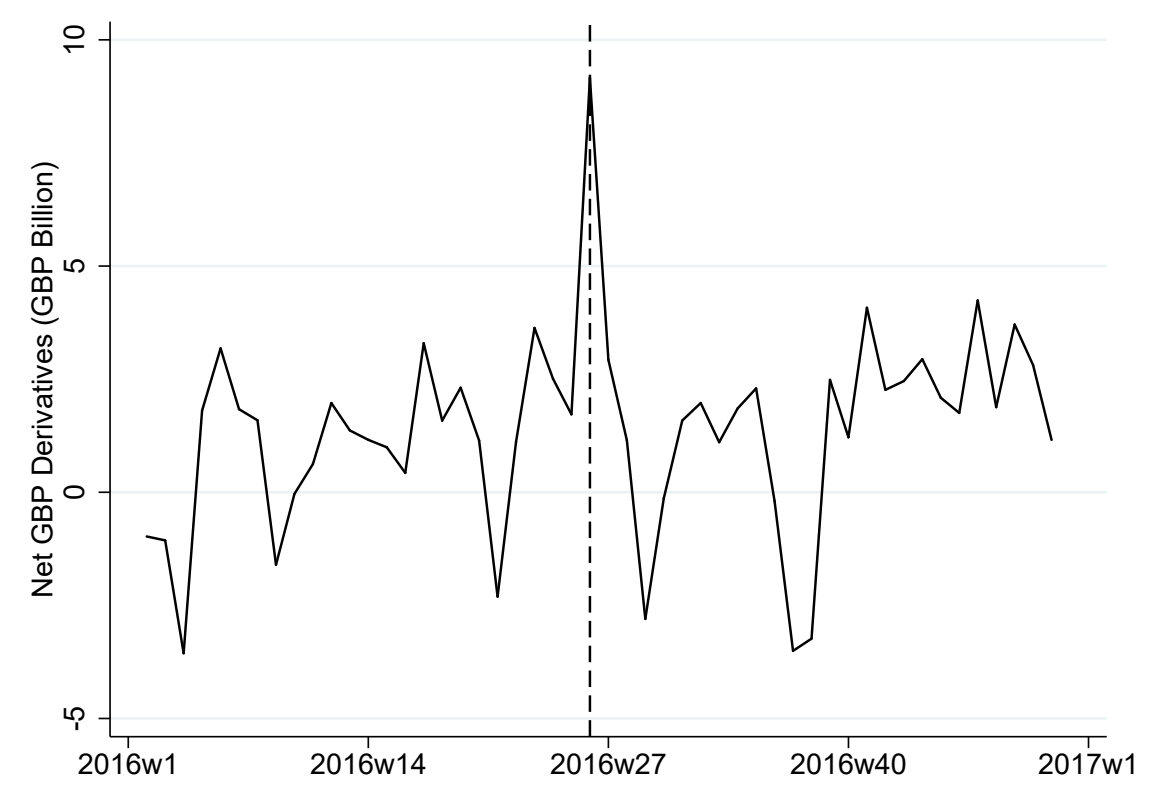

Notes: This figure shows the net notional value of GBP sold forward by banks. "Net" refers to GBP sold forward minus GBP bought forward. The first vertical line indicates the announcement of the Brexit referendum in week 8 of 2016. The second vertical line indicates the Brexit referendum in week 26 of 2016. Sources: Supervisory transactionlevel derivatives available under European Markets Infrastructure Regulation (EMIR) and authors' calculations. 
Figure A5: Net (Long) GBP Derivatives Exposure across Banks

(a) Maturing before June 30, 2016

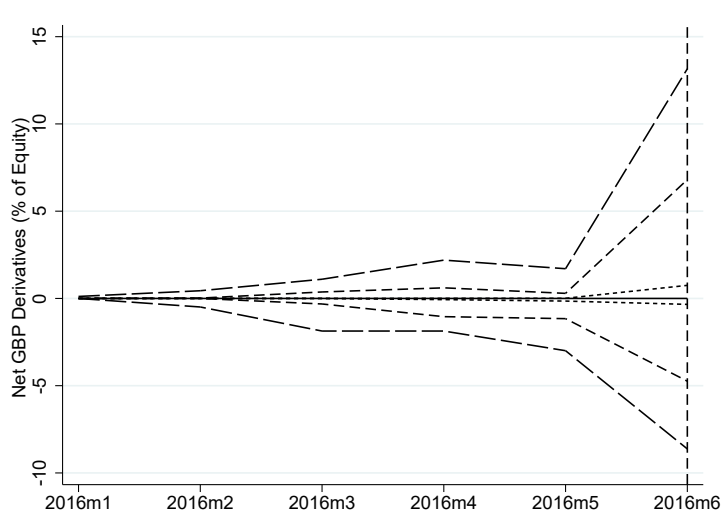

(b) On balance sheet

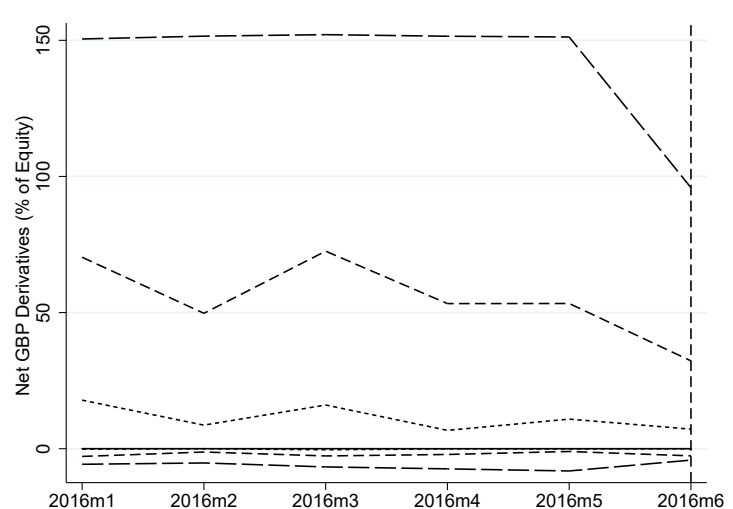

(c) On and off balance sheet

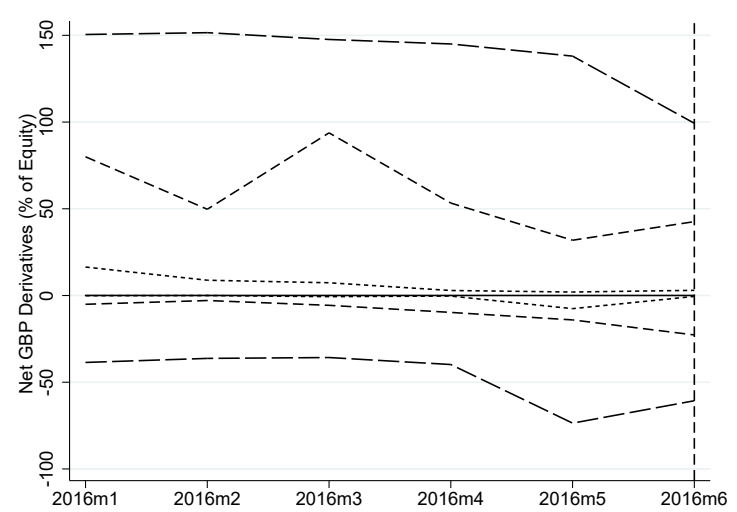

Notes: The three subfigures are similar to those in Figure 5. Panel (a) reports exposure that excludes contracts that mature past the regulatory reporting date of June 30, 2016. Panel (b) shows on-balance-sheet net GBP assets. Panel (c) shows combined on-balance-sheet net GBP assets and net long GBP derivatives exposure. Sources: Supervisory transaction-level derivativesavailable under European Markets Infrastructure Regulation (EMIR) and authors' calculations. 
Figure A6: Balance Tests

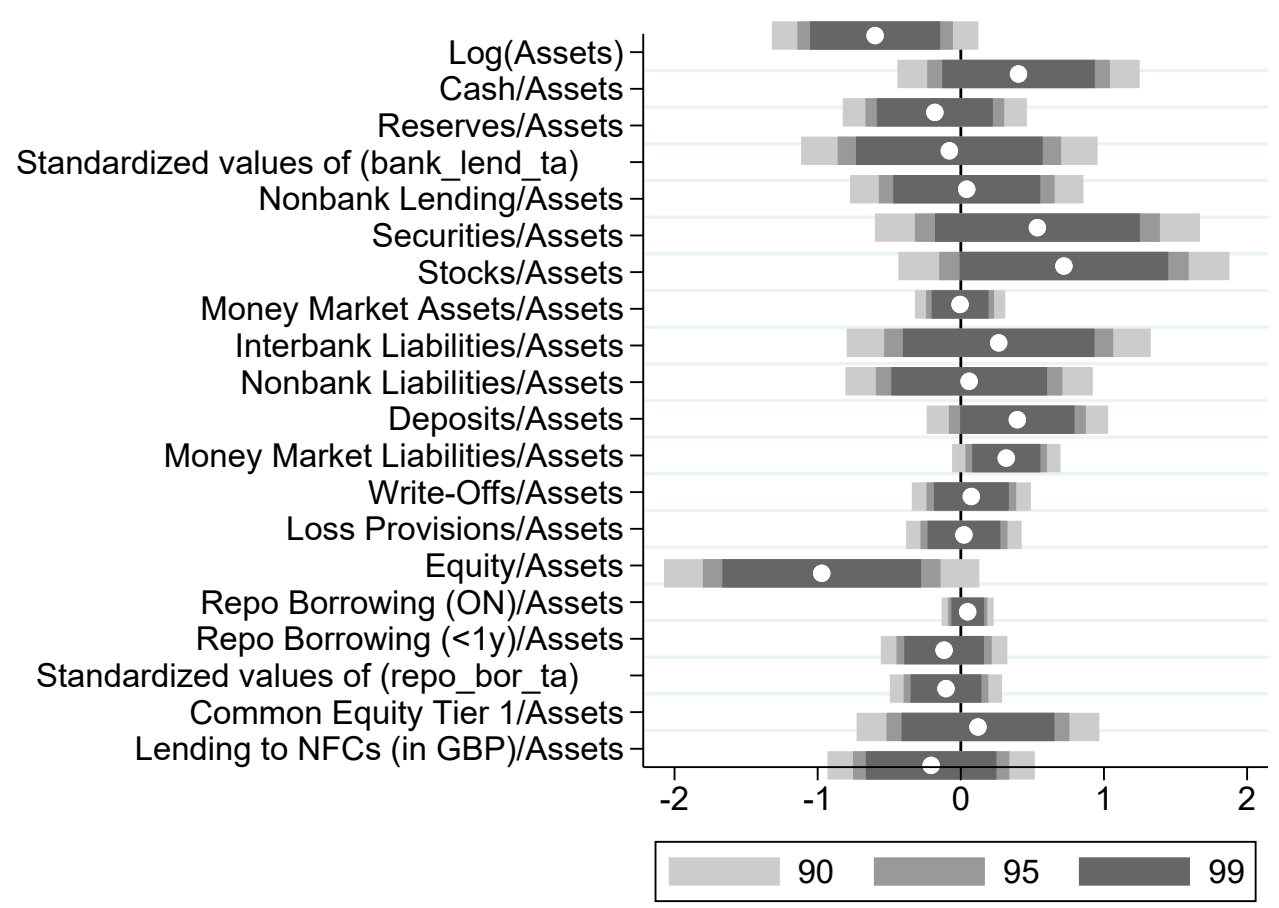

Notes: Covariate balance test of banks' balance sheet information for credit regression in Table 8. Sources: Banks' external positions (AUSTA), balance sheet statistic (BISTA), and authors' calculations. 
Figure A7: Pre-Trend and Persistence of Credit Effect

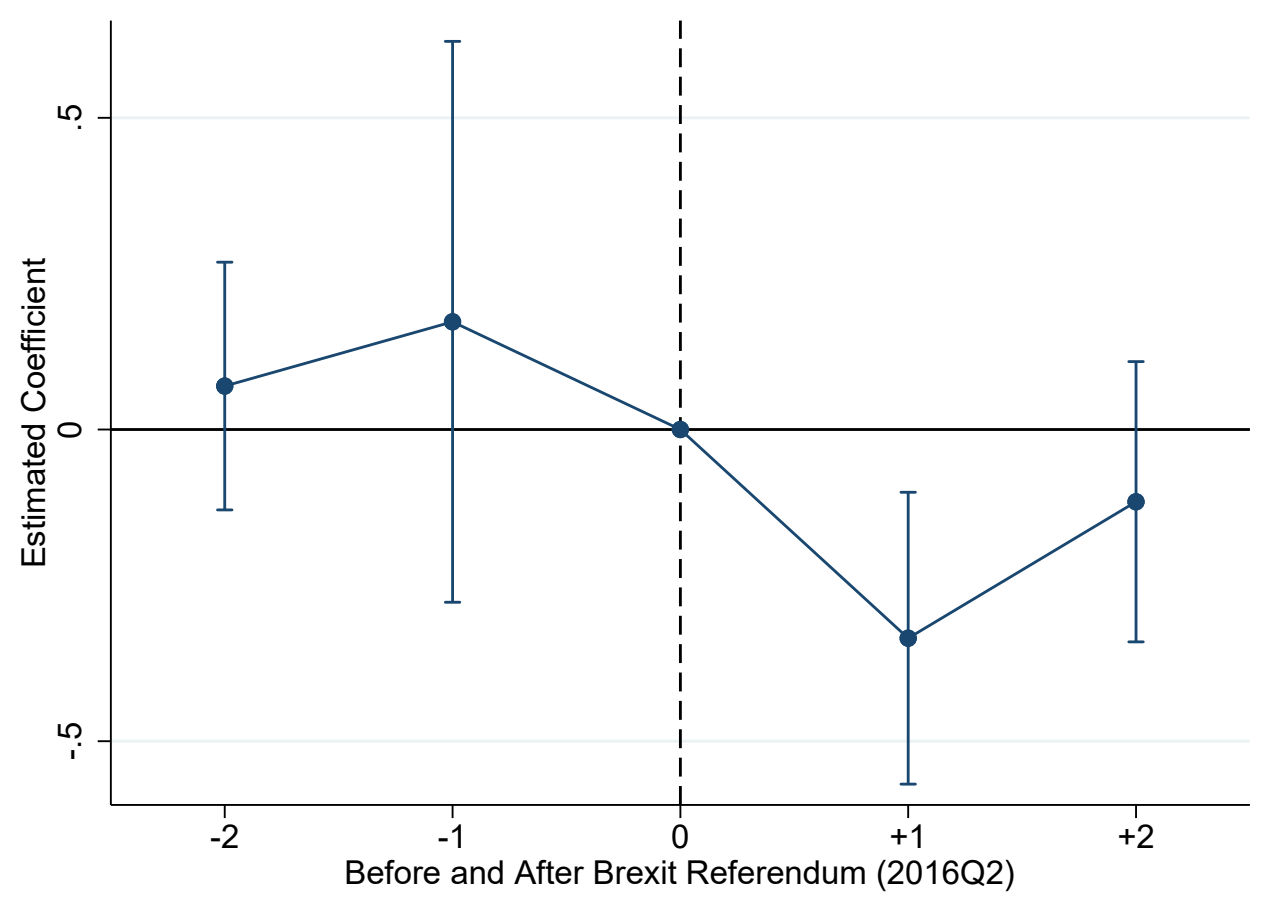

Notes: Baseline effect for different time periods. The regression follows that of Table 8, column (1), but the dependent

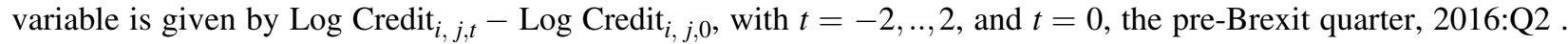
Whiskers indicate 95 percent confidence bounds. Sources: Supervisory transaction-level derivatives available under European Markets Infrastructure Regulation (EMIR), banks' external positions (AUSTA), balance sheet statistic (BISTA), German credit register, and authors' calculations. 
Figure A8: Aggregate Investment

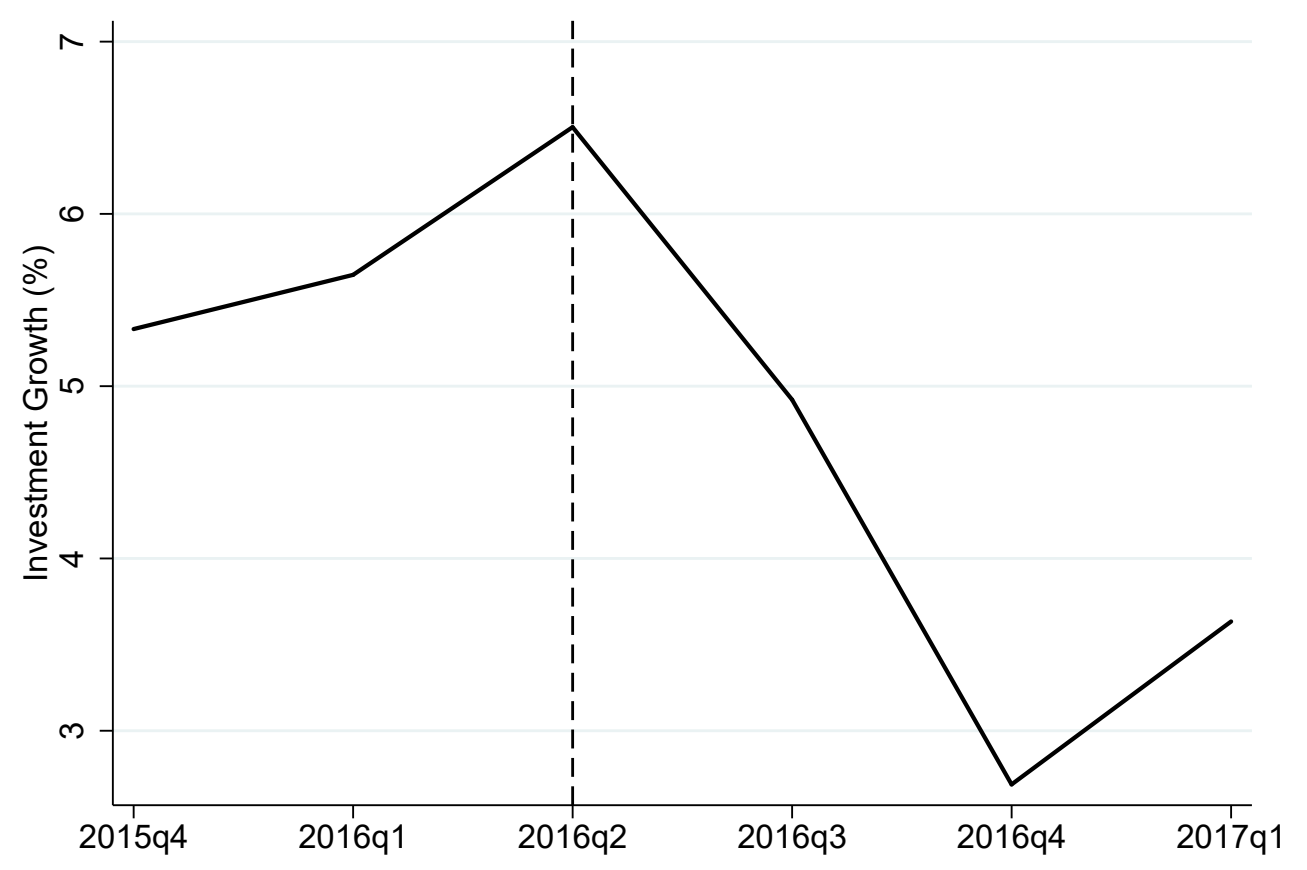

Notes: Year-over-year investment growth around Brexit. Sources: European Central Bank's statistical data warehouse and authors' calculations 
Table A1: Exchange-Rate Uncertainty and Firms' GBP Forward Usage

\begin{tabular}{|c|c|c|c|}
\hline \multicolumn{4}{|c|}{ Panel A: Data Collapsed by Pre-/Post-Announcement } \\
\hline & $\begin{array}{l}\text { Firm Entry (0/1) } \\
\text { (1) }\end{array}$ & $\begin{array}{c}\log (\text { Total Notional }) \\
\text { (2) }\end{array}$ & $\begin{array}{c}\text { Net Sell (\% Tot. Not.) } \\
\text { (3) }\end{array}$ \\
\hline Post-Announcement & $\begin{array}{l}0.3498 * * * \\
(0.006)\end{array}$ & $\begin{array}{l}0.2262 * * * \\
(0.038)\end{array}$ & $\begin{array}{c}-0.0156 \\
(0.011)\end{array}$ \\
\hline Constant & $\begin{array}{l}0.6502 * * * \\
(0.006)\end{array}$ & $\begin{array}{c}1.4074 * * * \\
(0.036)\end{array}$ & $\begin{array}{c}0.0838 * * * \\
(0.008)\end{array}$ \\
\hline Observations & 11,894 & 12,537 & 12,537 \\
\hline
\end{tabular}

Panel B: Weekly Data with VIX Uncertainty Measure

\begin{tabular}{lccc}
\hline & Derivative Usage (0/1) & Log(Total Notional) & Net Sell (\% Tot. Not.) \\
\cline { 2 - 4 } & $(1)$ & $(2)$ & $(3)$ \\
\cline { 2 - 4 } $\log ($ GBP Volatility Index $)$ & $0.0066^{* *}$ & $0.0892^{*}$ & 0.0155 \\
Constant & $(0.003)$ & $(0.046)$ & $(0.013)$ \\
& $0.1440^{* * *}$ & $0.6086^{* * *}$ & -0.0124 \\
Observations & $(0.007)$ & $(0.123)$ & $(0.035)$ \\
\hline
\end{tabular}

Notes: The table shows firms' forward usage in response to increased uncertainty. In Panel a, the data are collapsed into a pre-Brexit-announcement period (October 10, 2015, through February 22, 2016) and post-Brexit-announcement period (February 23, 2016, through June 23, 2016); thus, for each firm, there are two o bservations. Panel $b$ is at the weekly frequency (each observation is a firm-week) and uses the (lagged) GBP volatility index as an uncertainty measure. The dependent variable Firm Entry is a dummy variable equal to 1 if a firm is a new derivatives user after the announcement, and 0o otherwise (sample conditioned on firms with derivatives usage in the post-announcement period). Derivatives Usage is a dummy variable equal to 1 if the firm uses derivatives in a given week, and 0 otherwise. Total Notional is the notional value (in GBP million) of total forward contracts sold and bought. Net Sell is the difference between the notional values of contracts sold and contracts bought. Robust standard errors are clustered at the firm level and shown in parentheses. $* * * \mathrm{p}<0.01$, ** $\mathrm{p}<0.05$, $* \mathrm{p}<0.1$. Sources: Supervisory transaction-level derivatives available under European Markets Infrastructure Regulation (EMIR), banks' external positions (AUSTA), balance sheet statistic (BISTA), Bloomberg, and authors' calculations. 
Table A2: Firm-Level Summary Statistics on GBP Forward Usage

\begin{tabular}{cccccccc}
\hline Panel A: Firm sells GBP forward & & & & & & \\
\hline & Mean & St. Dev. & p10 & p25 & p75 & p90 & Obs. \\
Pre-Announcement Period & & & & & & & \\
Total Notional (GBP Mio) & 103.12 & 702.19 & 0.08 & 0.50 & 24.61 & 125.67 & 5,773 \\
Number of Contracts & 15.25 & 71.38 & 1 & 1 & 6 & 20 & 5,773 \\
Average Maturity (Days) & 48.04 & 66.69 & 3 & 8.60 & 57 & 99.14 & 5,769 \\
Post-Announcement Period & & & & & & & \\
Total Notional (GBP Mio) & 106.52 & 748.71 & 0.11 & 0.63 & 27.33 & 142.10 & 5,112 \\
Number of Contracts & 16.00 & 75.23 & 1 & 1 & 8 & 23 & 5,112 \\
Average Maturity (Days) & 51.79 & 65.81 & 4 & 12 & 64 & 113 & 5,102 \\
& & & & & & & \\
Panel B: Firm buys GBP forward & & & & & & \\
\hline & Mean & St. Dev. & p10 & p25 & p75 & p90 & Obs. \\
Pre-Announcement Period & & & & & & & \\
Total Notional (GBP Mio) & 101.81 & 667.06 & 0.10 & 0.53 & 26.46 & 126.61 & 5,337 \\
Number of Contracts & 15.04 & 68.50 & 1 & 1 & 7 & 21 & 5,337 \\
Average Maturity (Days) & 40.01 & 60.10 & 3 & 6.32 & 48 & 89 & 5,334 \\
Post-Announcement Period & & & & & & & \\
Total Notional (GBP Mio) & 114.02 & 778.68 & 0.13 & 0.70 & 30.91 & 155.69 & 4,746 \\
Number of Contracts & 16.63 & 74.83 & 1 & 1 & 8 & 23 & 4,746 \\
Average Maturity (Days) & 42.78 & 64.09 & 3 & 7 & 50.67 & 95.60 & 4,745 \\
\hline
\end{tabular}

Notes: The table shows summary statistics of firms GBP forward usages broken down by sell and buy, and by two periods: the period before the Brexit referendum was announced (from October 10, 2015, through February 22, 2016) and the period between the announcement date and the actual referendum date of June 23, 2016. Sources: Supervisory transaction-level derivatives available under European Markets Infrastructure Regulation (EMIR), banks' external positions (AUSTA), balance sheet statistic (BISTA), and authors' calculations. 
Table A3: Industry-Level GBP Hedging and Exposure at Brexit Announcement

\begin{tabular}{lcc}
\hline & Net Short (GBP billion) & Net Short (\% Gross Notional) \\
\hline Communication Services & 0.48 & 32.12 \\
Consumer Discretionary & 11.64 & 46.54 \\
Consumer Staples & 0.93 & 19.78 \\
Energy & -0.19 & -15.19 \\
Financials & -17.60 & -1.79 \\
Health Care & 0.55 & 7.31 \\
Industrials & 1.38 & 10.81 \\
Information Technology & 0.57 & 27.03 \\
Materials & -0.77 & -17.99 \\
Utilities & 0.92 & 5.42 \\
NA & 2.09 & 1.82 \\
\hline
\end{tabular}

Notes: The table shows, by industry, the net short GBP exposure on the day of the Brexit referendum. Firms are grouped into industries following the S\&P Global Industry Classification Standard (GICS). Sources: Supervisory transactionlevel derivatives available under European Markets Infrastructure Regulation (EMIR) and authors' calculations. 
Table A4: GBP Hedging and Net Trade with United Kingdom

\begin{tabular}{lcc}
\hline & \multicolumn{2}{c}{ Net Short at Brexit Referendum } \\
& $(1)$ & $(2)$ \\
\hline Net Imports from U.K. & $0.3740^{*}$ & $0.3382^{*}$ \\
& $(0.193)$ & $(0.167)$ \\
& & \\
Observations & 290 & 457 \\
R-squared & 0.079 & 0.069 \\
Country FE & Yes & Yes \\
Industry FE & Yes & Yes \\
\hline
\end{tabular}

Notes: The table shows the relationship between a firm's net GBP short position at the Brexit referendum date and the net imports to the United Kingdom in 2015. Net imports are measured as industry-level net imports. Column (1) is based on trades in goods, while column (2) is based on trade in goods and services. Robust standard errors are clustered at the industry level and shown in parentheses. ${ }^{* * *} \mathrm{p}<0.01, * * \mathrm{p}<0.05, * \mathrm{p}<0.1$. Sources: UN Comtrade database and authors' calculations. 